\title{
Visión panorámica del "Montblanc de España": apropiación y reinterpretación del referente alpino en el relato geográfico de Sierra Nevada (1800-1930)
}

\author{
Panoramic view on the 'Montblanc de España': appropriation \\ and reinterpretation of the Alpine model in the geographic narrative \\ on the Sierra Nevada (1800-1930)
}

\author{
Carlos Cornejo Nieto ${ }^{1}$ (1)
}

\section{Resumen}

La historia del conocimiento geográfico de Sierra Nevada no ha sido rigurosamente abordada desde una perspectiva relacional dentro del contexto del fenómeno global europeo de la interpretación de la montaña. Desde ahí, el artículo propone como hipótesis que el discurso geográfico decimonónico sobre la Sierra estuvo determinado por la apropiación del referente alpino a través de unos determinados recursos convencionales. Mediante el análisis hermenéutico comparativo de documentación narrativa y gráfica sobre ambos sistemas montañosos, se analiza la relevancia que tuvieron la transmisión, apropiación y reinterpretación de métodos, modelos de representación y estrategias narrativas foráneas, conformados a partir de la aplicación de la visión panorámica al estudio de los Alpes, en la legitimación del relato geográfico moderno de Sierra Nevada a través de la obra de Simón de Rojas Clemente y Rubio y Juan Carandell. Recurriendo al marco teórico de las geografías de recepción, se discuten las implicancias epistemológicas de la aplicación y extrapolación de dichos métodos y estrategias en la montaña nevadense. Se concluye que la Sierra constituyó un complejo espacio epistemológico periférico de reinterpretación hermenéutica del paradigma de la alta montaña alpina. De este modo, se infiere que la interpretación geográfica del macizo osciló entre la pretendida universalidad del discurso canónico importado de la alta montaña europea y el reconocimiento de una identidad geográfica diferente que se correspondiera con los particularismos del macizo.

Palabras clave: Sierra Nevada; Alpes; geografías de recepción; modelos de representación; visión panorámica; estrategias narrativas; Juan Carandell; Simón de Rojas Clemente y Rubio.

\begin{abstract}
The history of geographical knowledge of the Sierra Nevada has not been thoroughly addressed from a relational perspective within the context of the global phenomenon of European mountain interpretation. The article hypothesises that the nineteenth-century geographic discourse on the Sierra represented an appropriation of the Alpine model by several conventional resources. Through the comparative hermeneutic analysis of narrative and graphic materials on both mountain chains, the paper investigates the relevance of the transmission, appropriation, and reinterpretation of foreign methods, representational patterns, and narrative strategies, all shaped by a panoramic view in the study of the Alps in the legitimisation of the modern geographical narration on the Sierra Nevada. Moreover, by
\end{abstract}

1 Departamento de Geografía, Universidad de Concepción (Chile). carlcornejo@udec.cl 
using a theoretical framework of geographies of reading, the epistemological implications of the application and situatedness of using such methods and strategies in the Betic mountains are discussed. The article concludes that the Sierra was a complex peripheral epistemological space for a hermeneutic reinterpretation of the Alpine paradigm of high mountains. Thereby, it is inferred that the geographical interpretation of the massif varied between the alleged universality of the imported canonical discourse on European high mountains, and the recognition of a different geographic identity, corresponding to the particularisms of the Sierra's specificities.

Keywords: Sierra Nevada; Alps; geographies of reading; rendering models; panoramic view; narrative strategies; Juan Carandell; Simón de Rojas Clemente y Rubio.

\section{Introducción}

\subsection{La montaña europea en la historia del conocimiento geográfico}

Las montañas han ocupado un lugar protagónico en la historicidad del discurso geográfico occidental, ya sea desde perspectivas geofísicas y medioambientales como desde dimensiones de naturaleza cultural, política y simbólica. En la historia de la ciencia, la geografía histórica y la historia cultural europeas, la mayoría de los estudios sobre el tópico han estado (y, en gran medida, siguen estando) centrados en los sectores central y occidental de los Alpes y en los Pirineos centrales. Generalmente, esta literatura ha abordado el denominado "descubrimiento" cultural y científico del espacio de la alta montaña, atendiendo, por un lado, a sus correspondientes expresiones estéticas, filosóficas y literarias en el marco temporal de la modernidad (Beattie, 2006; Colley, 2010; Reichler, 2002) o en el de épocas anteriores (Korenjak, 2017; Nicolson, 1963); y, por otro, a sus relatos y representaciones geográficas en el contexto de la construcción del conocimiento científico, la cultura visual y las transformaciones epistemológicas al amparo de la modernidad (Berdoulay y Saule-Sorbé, 1998; Bigg, Aubin y Felsch, 2009; Billing, 2019; Briffaud, 1994; Broc, 1991; Klonk, 2003; Speich, 2009; Stafford, 1984). Asimismo, se han investigado las proyecciones políticas y patrimoniales de unos determinados paisajes montañosos icónicos en el marco de ciertas políticas de memoria y sus correlatos identitarios de la nación (Armiero, 2011; Mathieu, 2009), así como las implicaciones sociales, ideológicas e institucionales de las actividades montañistas insertas en las empresas coloniales e imperialistas europeas (Hansen, 2013; Moraldo, 2013; Ring, 2000).

La Geografía histórica española también ha mostrado interés académico por los paisajes montañosos nacionales. Los estudios más significativos han tratado el encuentro con la montaña desde aproximaciones culturalistas similares a los de la geografía francófona, proponiendo una lectura simbólica de la cumbre a la luz de ciertos relatos dominantes de la cultura europea moderna (Martínez de Pisón, 2000, 2004; Ortega Cantero, 2012). Se han abordado también las proyecciones políticas de paisajes de montaña emblemáticos dentro de los discursos sobre la memoria y las distintas identidades nacionales o regionales peninsulares de territorios como Castilla, Asturias, Aragón y Cataluña (entre otros), este último al alero de análisis similares desarrollados en Francia (Acín Fanlo y Lampre Vitaller, 2002; Nogué, 2005; Nogué y Vicente, 2004; Ortega Cantero, 2005; Ortega Cantero y García Álvarez, 2009; Roma i Casanovas, 2004). Finalmente, se ha puesto de relevancia el papel de las cordilleras peninsulares en la consolidación de la cultura científica y el pensamiento geográfico nacionales en los contextos de la Ilustración, el regeneracionismo y el krausismo (Mateu Bellés, 2008; Ortega Cantero, 2001). Respecto de Sierra Nevada (caso de estudio de este artículo), el relato histórico de su conocimiento se ha articulado, por un lado, en torno a los personajes célebres que participaron en la sistematización tanto de su aproximación científica como de su valoración cultural, y, por otro, a varios aspectos de la Sierra relacionados con las iniciativas económicas y sociales locales, como han sido, por ejemplo, las actividades del turismo, los deportes de invierno y otras formas de montañismo (Titos Martínez, 1997, 2014). Por otra parte, se ha abordado la genealogía del conocimiento geográfico del macizo a través del estudio historiográfico de la abundante documentación acerca de la montaña nevadense (Gómez Ortiz y Plana Castellví, 2006; Gómez Ortiz, Milheiro Santos y Serrano Giné, 2008; Gómez-Ortiz, Palacios, Schulte, Salvador-Franch y Plana-Castellví, 2009), sin apenas dotar a este corpus documental de una contextualización cultural y epistemológica relacional que lo situara en el contexto europeo de los avances de las ciencias de la tierra.

Gran parte de la literatura internacional referida ha evidenciado unos abordajes poco relacionales y a menudo autorreferenciales, apuntalados sobre una supuesta singularidad emanada de cada caso de estudio, sin prestar una rigurosa atención a los posibles diálogos transnacionales que se hayan podido dar 
entre formas de interpretación, sistemas de conocimiento y modelos de representación de las distintas geografías de montaña continentales. Por su parte, los diversos enfoques de la geografía española han sido también poco proclives a explorar con profundidad los orígenes y las connotaciones de dichos sistemas y modelos discursivos dentro de unos determinados contextos científicos, culturales y epistemológicos en una escala europea y de manera relacional. Como contraparte a esta desatención generalizada, han aparecido recientemente otras investigaciones que proponen enfoques dialógicos entre lo universal del fenómeno de la interpretación científico-cultural de la montaña y lo particular de sus respuestas localizadas, problematizando así los sistemas montañosos como nodos de transmisiones intelectuales transnacionales a la luz de la movilidad de los discursos, las tecnologías y los modelos de interacción con las geografías verticales (Cornejo Nieto, 2015, 2018; Della Dora, 2011, 2016; Kakalis y Goetsch, 2018), y planteando miradas comparativas que permitan relevar aspectos comunes y diferencias particularizadas en la construcción discursiva de diversos sistemas de montaña (Anderson, 2020; Cosgrove y Della Dora, 2008; Debarbieux y Rudaz, 2015; Frolova, 2001, 2006).

\subsection{Referentes: métodos, recursos narrativos y modelos de representación en Alpes y Pirineos}

Paradójicamente, y a pesar de las limitaciones que presenta la literatura mencionada referente a Sierra Nevada, el macizo andaluz se consolidó como objeto de estudio significativo dentro del circuito europeo del conocimiento geográfico de la alta montaña desde los primeros años del siglo XIX, debido, en gran medida, a las continuas relaciones - certeras en mayor o menor grado- que se establecieron entre él y la alta montaña europea. No en vano, a lo largo de toda la centuria, la relevancia del macizo se vio mediatizada por las constantes analogías con los sectores central y occidental de los Alpes y, en menor medida, con los Pirineos, ambas cordilleras exploradas y estudiadas con anterioridad. Las comparaciones entre estas grandes cadenas montañosas del continente (especialmente Alpes) y la Sierra fueron frecuentes en las interpretaciones de los autores foráneos y nacionales que visitaron Granada. Ya fuera desde dimensiones estéticas o científicas, sus representaciones y aproximaciones acerca de los "los majestuosos Alpes de Granada" (Capell Brooke, 1831, p. 214), los "Alpes andaluces" (Boissier, 1839), el "Montblanc de España" (Carandell Pericay, 1920) o la "hermana de los Alpes" (Bernaldo de Quirós, 1923, p. 10), estuvieron condicionadas por el referente científico-cultural alpino, que se presenta a continuación. Lejos de ser un mero recurso analógico para conceptualizar el macizo andaluz, este recurrente parangón deja entrever la jerarquía que alcanzó la cordillera centroeuropea como referente hegemónico ineludible para entender las claves del conocimiento normativo de la época en torno a las geografías de montaña del continente.

A partir del siglo XVIII, los científicos de la tierra experimentaron un notable interés por la explicación del orden estructural de la superficie terrestre. Para abordar tal desafío, aplicaron el método de la visualización panorámica desde las cumbres, el cual no solo se reveló como un nuevo procedimiento metodológico, sino que también se convirtió en un "tópico explícito de reflexión", especialmente entre aquellos naturalistas pertenecientes al círculo científico de Ginebra, como Charles Bonnet, Jean Senebier, Horace-Bénédict de Saussure, Jean-André Deluc y Benjamin Carrard (Bigg, 2007, p. 76; Billing, 2019, p. 65). De importantes repercusiones para las ciencias geográficas, dicha operación visual, ejercida desde las cumbres de la cordillera de los Alpes y de naturaleza móvil, global e integradora, generó unos determinados modelos de representación gráficos y unas estrategias narrativas en la literatura científica de la época, que aún seguirían empleándose a lo largo de la centuria siguiente. Dichos recursos estuvieron conformados por las vistas panorámicas, ya fuera bajo los formatos de dibujos, croquis o écfrasis descriptivas, y los tours d'horizon o panoramas circulares, dibujados a mano alzada sobre el terreno y, a veces, pintados posteriormente.

Los panoramas fueron uno de los formatos de representación más determinantes para la transformación de la cultura visual y científica modernas desde el siglo XVIII, abriendo paso a un acceso nuevo al conocimiento que se traduciría en nuevas formas de control del territorio y desciframiento racional del paisaje (Charlesworth, 2010), estandarización de un tipo concreto de producción de verdad y de "visión normativa" (Crary, 1990, p. 20; Oettermann, 1997, p. 7), y representación pública espectacularizada de paisajes de difícil acceso (Della Dora, 2007). El formato panorámico funcionó como una tipología tanto de representación visual como de técnica descriptiva que organizaba los componentes geográficos del territorio que la operación móvil de la mirada del sujeto recogía desde un punto elevado (Naranjo Ramírez y López Ontiveros, 2011). Una modalidad circular de este formato fueron los llamados tours d'horizon, representaciones anamórficas de vistas panorámicas completas de $360^{\circ}$ obtenidas desde las cimas de las 
montañas que reproducían el alzado del relieve mediante la aplicación de una "mirada circular y envolvente" (Naranjo Ramírez y López Ontiveros, 2011), funcionando como "una respuesta a la noción de totalidad" contemplada activamente desde un punto de observación (Comment, 2002, p. 166).

Los miembros del círculo científico de Ginebra fueron conscientes de los desafíos que presentaba la aplicación de este tipo de visión como metodología complementaria a la ascensión a la cumbre. Horace-Bénédict de Saussure fue uno de los pioneros tanto en aplicar este método como en reflexionar acerca de su pertinencia, manifestando su interés personal por "ascender las cimas elevadas donde el ojo pueda abarcar a la vez una multitud de objetos" (Saussure, 1779, p. III) a fin de obtener una "visión total, panorámica, que ofrecería un dominio completo del espacio" (Reichler, 2002, p. 59). Convencido de que el estudio de las montañas era la única forma en que se "puede acelerar el progreso de la teoría del globo" (Saussure, 1787, p. VI), y consciente de la novedad que implicaba el uso de la mirada exploratoria sobre la estructura del sector occidental de los Alpes, el ginebrino vio la necesidad de traducir este método en nuevas tipologías de representación, tanto textuales como gráficas, que pudieran vehicular con precisión esta nueva aproximación al paisaje. Así, los fragmentos de escritura descriptiva panorámica se reiteraron en toda su obra. En una sección del relato, Saussure (1779, pp. 102-103) ofrecía un "vistazo general ("coup-d'oeil") sobre una parte de la cordillera, procedimiento a través del cual fraccionó la cordillera en imágenes parciales con el objetivo de presentar distintas secciones panorámicas para analizar la formación geológica de la montaña. Los resultados fueron mostrados en varios coup-d'oeil narrativos de distintos sectores cordilleranos, que le sirvieron al autor para reconstruir visualmente, primero de manera segmentada, su orden geográfico, para después abordar la interrelación de dichas partes como una totalidad.

Además de las écfrasis panorámicas, Saussure creó un innovador modelo de representación gráfica del paisaje: la primera vista circular anamórfica de la alta montaña publicada hasta entonces, levantada entre 1766 y 1770 por el escritor y dibujante Marc-Théodore Bourrit (1739-1819) para su libro Description des glacières et glaciers de Savoye, publicado en 1773 (Figura 1).

Figura 1. Marc-Théodore Bourrit: Vue circulaire des Montagnes qu'on découvre du sommet du Glacier de Buet

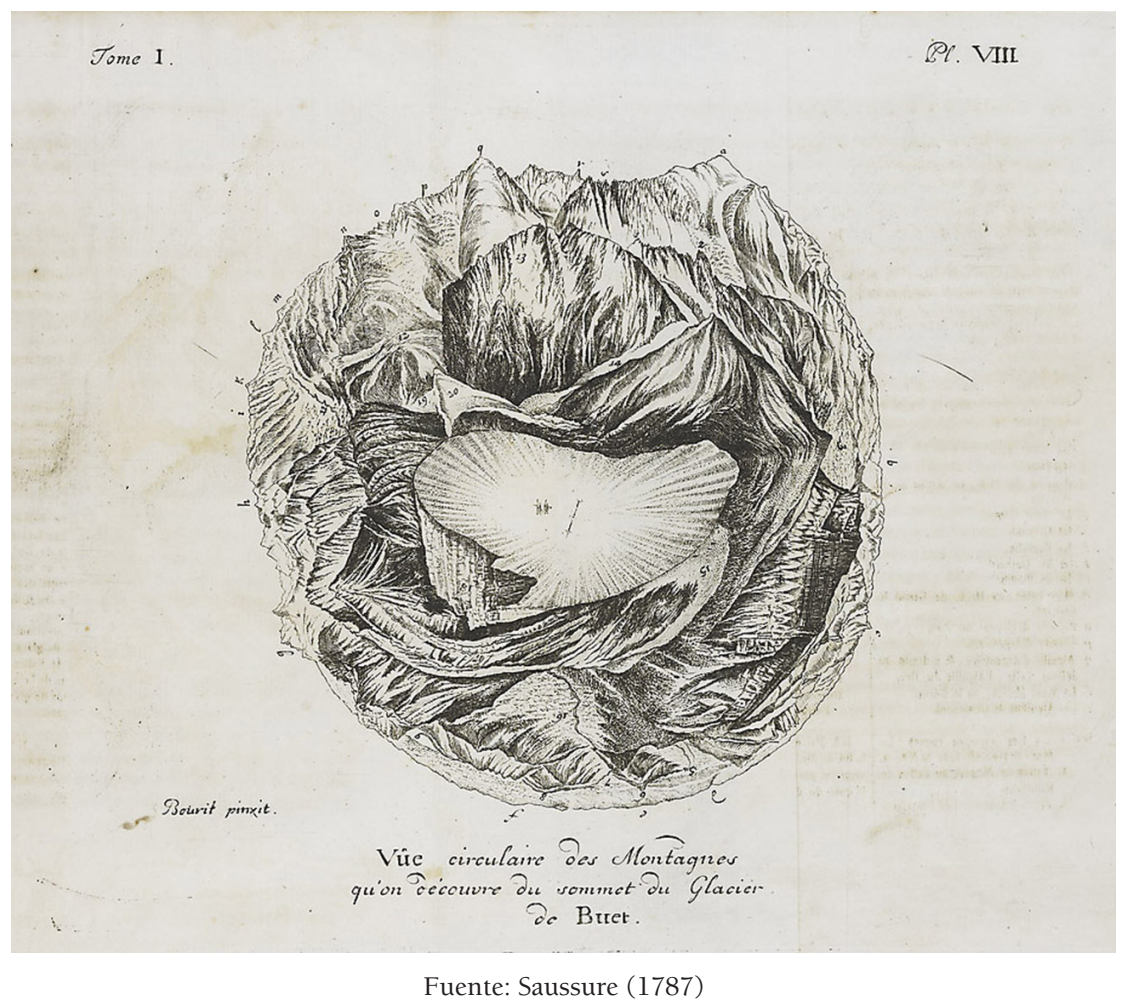

Según Saussure (1779), el célebre tour d'horizon pretendía sustituir las "vistas ordinarias" (p. 496) e ineficaces empleadas hasta entonces a fin de plasmar el ordenamiento sistemático de los "objetos infinitamente variados" que se apreciaban desde la cumbre (p. 495), de manera que se vieran "todos los objetos relacionados entre ellos y absolutamente tal como se presentan a un observador situado sobre la cima de 
la montaña" (p. 496). El formato panorámico iba acompañado de su correspondiente explicación, en la que Saussure subrayó tres aspectos fundamentales: el papel dominante del sujeto que ejercía la mirada racional sobre la naturaleza, la cualidad móvil de tal mirada panorámica y la trascripción al papel de su aplicación en base a leyes de perspectiva:

Hay que poner en el dibujante un singular esfuerzo de atención, y una aplicación difícil de las reglas de la perspectiva para proyectar sobre los planos verticales y las líneas derechas de los objetos que él ve realmente sobre las circunferencias y en el interior de un número de círculos cuyo ojo suyo sea el centro. (...) siguiendo el método que he empleado, el dibujante pinta los objetos exactamente como los ve girando su papel a medida que él mismo gira. Y aquellos que (...) quieran formarse una idea de los objetos que ha dibujado, sólo tienen que imaginar que están colocados en el centro del dibujo, (...) y, girando el dibujo, hacer la revisión de todas sus partes. (Saussure, 1779, pp. 496-497).

Todos los elementos del espacio geográfico, desplegados en derredor, aparecían ilustrados en perspectiva en torno al punto central, "como si se presentaran a un ojo situado en el mismo punto, y que sucesivamente da la vuelta a todo su horizonte" (Saussure, 1787, p. 326). Extendida sobre el papel, la imagen se complementaba con su correspondiente leyenda, una nomenclatura alfabética que indicaba el nombre y la ubicación de las cumbres extendidas en la silueta del horizonte circular, traduciendo la doble estrategia de Saussure de conjugar la más exacta descripción topográfica posible con la expresión singular de su plasmación gráfica (Billing, 2019, p. 71; Klonk, 2003). El resultado fue un ingenioso y sofisticado dispositivo icónico-textual que pronto se convirtió en epítome de la proyección gráfica de la exploración moderna de la montaña y de la sistematización geográfica de su relieve.

El dominio de este método visual y la calidad de ejecución de su modelo perspectívico favoreció la producción gráfica de formatos panorámicos en la cultura geográfica francófona a lo largo de la modernidad, dotando a la montaña de una legibilidad verosímil, racional e inédita hasta entonces ${ }^{2}$. Entre los ejemplos más notables, ya en el primer cuarto del siglo XX, destacaron los panoramas levantados y pintados a la acuarela por el geodesta y alpinista Paul Helbronner, quien cartografió la parte francesa de la cordillera con mapas a gran escala, publicados en su obra en doce volúmenes Description géometrique des Alpes Françaises entre 1910 y 1938. En ella, el autor reunía los relatos de sus ascensiones, los cálculos detallados de sus mediciones geodésicas y las ilustraciones y tours d'horizon fotográficos —más tarde transformados en panoramas acuarelados- (Guilhot, 2005, p. 24), que reafirmaban, sobre el soporte bidimensional del papel, la complementariedad metodológica entre el desplazamiento físico a las cumbres y la aplicación de las técnicas de visualización panorámica desde distintas estaciones geodésicas. Las triangulaciones de Helbronner generaron 270 panoramas circulares, si bien entre su producción gráfica destacaron una serie de acuarelas sobre fotograbados de grandes vistas panorámicas de la montaña, las cuales, como se verá más tarde, tuvieron una importancia fundamental en los estudios de Juan Carandell sobre Sierra Nevada.

Entre sus acuarelas, destacaron dos, tanto por la calidad geográfica y estética de su ejecución como por el gran formato empleado: el Tour d'horizon depuis le sommet du Mont Blanc, impreso en 12 planchas con una longitud de algo más de 7 metros, y la Représentation panoramique du sommet du Pelvoux, organizada en 10 planchas y de una longitud de 6 metros, dibujadas y pintadas a la acuarela en 1899 y 1902 respectivamente (http://www.helbronner.org/) (véanse las imágenes en http://bibliotheque-dauphinoise. blogspot.com/2010/11/paul-helbronner-1871-1938.html). Las dos técnicas artísticas utilizadas en cada panorama (dibujo y acuarela) recogían distintos componentes geográficos del sistema montañoso. Por un lado, la parte inferior de cada plancha estaba ocupada por el perfil de montañas dibujado a plumilla con utilización de sombreados, mostrando la orientación de los cordales de la cordillera, las altitudes y toponimia de cimas y valles, la ubicación de las masas glaciares y la articulación entre macizos, cumbres y collados; todo ello desplegado horizontalmente como un gran sistema. Por otro lado, las tres cuartas partes restantes de cada plancha estaban reservadas al horizonte panorámico del perfil inferior pintado con acuarela, técnica que le permitió a Helbronner destacar con detalle la geomorfología de los macizos, el estado de los glaciares, la disposición granítica de las paredes verticales y los roquedos, la apariencia

2 Otros científicos montañistas suizos, como Augustin Schmid y F. L. Pfyffer von Wyher, con su Panorama circular dibujada desde la montaña Rigi al Kulm, de 1815; Elias Emanuel Schaffner, con su Panorama des Alpes Rhétiennes du Haut-Engadin, realizado desde la cumbre del Mont Rosatsch en 1836, constituyeron algunos ejemplos elocuentes de la celebridad que alcanzó este formato (Comment, 2002, p. 166; Saule-Sorbé, 2004, p. 214; Della Dora, 2016). 
de los canchales, las condiciones nivológicas de la montaña y, sobre todo, el despliegue de todo el orden geográfico de los cordales. Las dos técnicas quedaban integradas en el resultado final de la impresión, revelando, tanto en la representación pictórica en sí como en el soporte impreso utilizado para su publicación, las nociones de totalidad y globalidad a las que aspiraba la mirada panorámica.

Las técnicas de observación móvil y los modelos de representación panorámicos no tardaron en circular desde el mundo alpino hasta los Pirineos. Louis-François Ramond de Carbonnières (1755-1827) aplicó el mismo procedimiento desde las cumbres del Monte Perdido desde la década de 1780, declarando, como buen conocedor de la obra de Saussure, que "cuando se ha visto la primera de las montañas graníticas [el Mont-Blanc], falta por ver la primera de las montañas calcáreas [el Mont-Perdu]" (Ramond de Carbonnières, 1801, p. 115). Acompañado de su instrumentalización científica, aunque persuadido del uso maestro del ojo humano como herramienta fundamental, afirmó que desde lo alto de la cumbre "una mirada era suficiente; el caos estaba desenredado" (Ramond de Carbonnières, 1789, p. 45). En su obra, la mirada panorámica ejercida sobre el paisaje geográfico fue también trasladada a las representaciones de los perfiles del sector central de la cordillera mediante dibujos-diagrama realizados por él mismo (Cornejo Nieto, 2015). La composición de estas imágenes permitía integrar "todos los objetos que había examinado de forma aislada", mostrando el macizo del Monte Perdido como un sistema global de partes conectadas y "relaciones generales que mediante las observaciones detalladas solo estaban entregadas a conjeturas" (Ramond de Carbonnières, 1801, pp. 283-284). El uso de este método en Pirineos alcanzaría cotas más elevadas con la contribución del pintor y geógrafo Franz Schrader, quien perfeccionó, a finales de siglo, esta forma de sistematizar los componentes de la montaña a través de sus vistas circulares panorámicas u orografías (Berdoulay y Saule-Sorbé, 1998; Saule-Sorbé, 2004).

\subsection{Objetivos}

Atendiendo a estos referentes europeos, el presente artículo postula la siguiente hipótesis: el conocimiento geográfico moderno y la consecuente producción científica en torno a "los Alpes andaluces" (Sierra Nevada) estuvieron determinados por un régimen discursivo geográfico, surgido previamente en el entorno del sector francófono de la cordillera alpina, y, algo más tarde, en Pirineos, que fue el resultado de la implementación de las estrategias metodológicas, los formatos tipológicos de representación y los recursos narrativos novedosos — basados en la aplicación de la visión panorámica- comentados en el epígrafe anterior; una discursividad de la montaña importada que conllevó importantes efectos en la creación y legitimación de un determinado relato geográfico sobre el macizo nevadense a lo largo de todo el siglo XIX y principios de la centuria siguiente.

Para atender a esta hipótesis, el artículo se sitúa en la dimensión interrelacional del fenómeno europeo del conocimiento geográfico de las cumbres, mencionado anteriormente. Desde ahí, se plantean dos objetivos: primero, analizar la movilidad, asimilación y reinterpretación de unos marcos epistémicos, procedimientos metodológicos, recursos narrativos y modelos de representación específicos, surgidos en el seno de la geografía alpina de la Ilustración, que participaron en la construcción del relato geográfico de Sierra Nevada a lo largo de la modernidad; y, segundo, discutir las consecuencias que tuvo, en el plano epistemológico, esta circulación de estrategias y recursos en la elaboración del discurso geográfico en torno a un macizo con particularismos muy marcados, como es Sierra Nevada, aún estudiado por entonces a través del referente alpino. Para abordar tales objetivos, el artículo se enfoca en las aportaciones del naturalista Simón de Rojas Clemente y Rubio (1777-1827) y el geógrafo Juan Carandell Pericay (1893-1937), dos autores españoles fundamentales para el conocimiento geográfico nevadense en dos momentos históricos y contextos científicos distintos de la modernidad, aunque ambos atravesados por la impronta de las geografías alpinas de montaña. Con ello, el artículo contribuye a los debates en torno a la historia del conocimiento geográfico de la montaña peninsular como fenómeno global de la cultura científica europea a partir de un contexto epistemológico y una cultura visual compartidos.

Tras la revisión de la literatura, la presentación de los referentes europeos a tener en cuenta para el análisis particular de Sierra Nevada y la formulación de la hipótesis y los objetivos, el artículo expone a continuación las características esenciales del área de estudio, las fuentes analizadas, el abordaje metodológico empleado en dicho análisis, y el marco teórico utilizado para la interpretación y posterior discusión de dichos materiales, centrado este último en las geografías de recepción del conocimiento. Seguidamente, el apartado de resultados realiza un análisis interpretativo de las fuentes textuales y gráficas de Clemente y Rubio y Carandell sobre Sierra Nevada, poniéndolas a dialogar con los referentes 
presentados de la montaña europea. Finalmente, el artículo cierra con una discusión acerca de las implicancias epistemológicas que tuvo la recepción discursiva del conocimiento de la montaña europea en la realidad geográfica de Sierra Nevada.

\section{Metodología}

\section{1. Área de estudio}

El artículo tiene como caso de estudio el macizo de Sierra Nevada (Granada), atendiendo especialmente a las altas cumbres de su cordal principal. El macizo se encuentra ubicado en la Zona Interna Bética de los Sistemas Béticos, formando, junto con el Rif, el arco Bético-Rifeño que se eleva junto al Mediterráneo, y alcanzando una altitud máxima de 3.482 metros sobre el nivel del mar en la cumbre del Mulhacén. Como es sabido, entre algunos de los particularismos más destacables del macizo se encuentran sus paisajes de alta montaña de tipo alpino por encima de los 2.500 metros de altitud, a pesar de distar tan solo 35 kilómetros del mar Mediterráneo; la amplia biodiversidad que albergan sus distintos ecosistemas debido a la relación entre la altitud de sus cumbres y su ubicación en una zona macroclimática de influencia mediterránea; y la variabilidad de la morfología de su relieve, marcada por la diferencia entre el agreste modelado glaciar de la vertiente norte y los paisajes culturales de las lomas de la vertiente meridional, con una notable presencia antrópica (Jiménez Olivencia, Porcel Rodríguez y Caballero Calvo, 2015; Platt, Behr, Johanesen y Williams, 2013).

\subsection{Fuentes y abordaje metodológico}

Abordar la dimensión relacional de la historia del fenómeno europeo del conocimiento geográfico de la montaña ha requerido una aproximación dialogada e interpretativa a las fuentes documentales sobre cordilleras y macizos continentales distintos —en este caso, los referentes de los Alpes y, en menor medida, Pirineos, y Sierra Nevada-. La complejidad de este enfoque ameritó adoptar dos abordajes metodológicos complementarios: por un lado, se trabajó con el método histórico de naturaleza comparativa, centrado en las fuentes primarias pertinentes, tanto textos como imágenes, sobre dichos sistemas montañosos; y, por otro, se empleó un método de análisis de dichos materiales de naturaleza hermenéutica.

Respecto del método histórico, se llevó a cabo un trabajo de archivo en el que se identificaron y seleccionaron algunos de los escritos e ilustraciones de naturaleza geográfica más significativos que participaron tanto en la formulación del discurso geográfico en torno a los Alpes y Pirineos como cordilleras referenciales, como en la construcción del relato geográfico en torno a Sierra Nevada. En este sentido, se han seleccionado aquellas fuentes que fueron configuradas a partir de la aplicación metodológica de la observación panorámica como vector articulador de las mismas y con distinta cronología dentro del arco temporal de la modernidad — desde la Ilustración hasta el primer cuarto del siglo XX-. Según este criterio de selección, el artículo hace una revisión de las aportaciones fundamentales de Horace-Bénédict de Saussure y Paul Helbronner en el ámbito alpino, y, en menor medida, en la de Louis-François Ramond de Carbonnières en la cordillera pirenaica. Sobre estos materiales, se realizó la debida contextualización histórica, epistemológica y cultural, atendiendo a sus circunstancias originales de producción, al valor de su contenido y a relaciones convenientes con otras imágenes y textos coetáneos que pudieran aportar información sobre la consolidación de la alta montaña como objeto de un nuevo conocimiento geográfico moderno. Respecto de Sierra Nevada, la investigación gira en torno a las aportaciones de Rojas Clemente y Rubio y Juan Carandell, ya que sus textos y representaciones de carácter científico se vieron asimismo atravesados, de una manera fundamental, por la operación de la mirada panorámica sobre el conjunto de las cumbres. Desde el punto de vista comparativo, se han cotejado los contenidos y formatos de los materiales mencionados, referentes a la montaña europea (Alpes y Pirineos), con los de las producciones narrativas y gráficas de estos dos últimos autores que trabajaron en Sierra Nevada.

Respecto del segundo método, se ha efectuado un análisis interpretativo de los contenidos y significados de los textos y las imágenes a partir del diálogo con literatura secundaria específica. En este sentido, se han empleado los procedimientos metodológicos planteados por Gillian Rose en su tratado sobre la interpretación de las imágenes en geografía (Rose, 2001), abordando las representaciones y, por extensión, las narrativas a partir de la distinción del "lugar de la producción", "el lugar de la imagen" (o del texto), y "el lugar de la recepción" (Rose, 2001). Siguiendo a Rose, se han tenido en cuenta dos aspectos en el análisis de los materiales: a) respecto a la contextualización científica: se ha situado la imagen o el texto 
dentro de los esquemas discursivos convencionales que vehiculizaron el conocimiento geográfico de las cumbres; y b) respecto a la contextualización cultural: se ha abordado la representación dentro de una cultura visual específica, definida por las técnicas de observación y el formato panorámicos, determinantes para la creación de los modelos gráficos del paisaje de montaña.

\subsection{Marco teórico: geografías de recepción del conocimiento}

Los materiales se interpretan recurriendo al marco teórico de las geografías del conocimiento, de muy escasa acogida en la academia española, inspirada por la "teoría nómada" o "itinerante" (travelling theory) del teórico palestino Edward Said. Said (1991) señaló que "las ideas y las teorías viajan", cuyas manifestaciones y resultados se ven "alimentados" y "sostenidos" por una constante movilidad de circulación de conocimientos, ya sea a través de una "influencia reconocida" o "inconsciente", que "posibilita la actividad intelectual" (p. 226). La historia de la ciencia también ha tratado la cuestión de la itinerancia de ideas y saberes científicos en la tradición moderna occidental. Bruno Latour (2001) ha planteado que el conocimiento, lejos de ser solo transferido desde lo que él denomina "centros de cálculo establecidos", es asimismo transformado mediante "operaciones de traducción" y "operaciones de persuasión" (Latour, 2001, pp. 90, 120). Asimismo, James Secord (2004) ha indicado que la circulación del conocimiento significa considerar cada texto, imagen, acción y objeto científico como el "indicio de un acto de comunicación, con receptores, productores y modos y convenciones de transmisión" (Secord, 2004, p. 661). Se trata, por tanto, de un "circuito" de comunicación que opera en múltiples direcciones (Secord, A., 2011 , p. 285), una red de intercambios y un proceso hermenéutico de traducción y resituación del conocimiento científico, al mismo tiempo incluyente y excluyente (Secord, J., 2004, p. 662), que son puestos en práctica en unos determinados espacios y mediatizados a través de formas impresas itinerantes (Curry, Jardine, Secord y Spary, 2018; Jardine, Spary y Secord, 1996).

La geografía anglosajona ha incorporado estos debates a la historia de la disciplina en la medida que ha asumido que la formulación de teorías y la producción de significados están condicionados espacialmente. En este sentido, autores como David Livingstone y Charles Withers, entre otros, han propuesto unas "geografías del conocimiento", o "de la interpretación" de las ideas ("geographies of reading"), del mundo moderno europeo a partir de la producción, recepción, extrapolación (o "traducción") y reinterpretación de los dispositivos de representación, las estrategias narrativas y los espacios físicos de textualidad que forman parte del discurso geográfico, analizando la relevancia que adquieren las particularidades geográficas locales en la transmisión y reformulación situada del conocimiento y las formas impresas en las que circulan (Della Dora, 2007; Livingstone, 2003, 2005; Withers y Livingstone, 2011). Como han indicado otros autores (Duncan y Gregory, 2010; Keighren y Withers, 2012), en este préstamo de ideas y formatos en continua circulación, la narratividad implícita en el relato científico se ha visto envuelta en estrategias autorales y procesos de traslación de teorías y procedimientos convencionales ya legitimados, establecidos en un centro y extendidos a otras geografías periféricas, dando como resultado espacios que, con frecuencia, son dimensionados por criterios ajenos a las cualidades geográficas locales.

\section{Resultados: interpretación geográfica de Sierra Nevada: asimilación de procedimientos metodológicos, formas de representación y recursos narrativos de origen alpino}

\subsection{Rojas Clemente: visión panorámica desde las cumbres nevadenses}

Las cumbres de Alpes y Pirineos se consolidaron como atalayas de observación del orden geográfico del paisaje. La normalización, en el plano epistemológico, de los métodos referidos hasta ahora, así como la movilidad, en el tiempo y el espacio, de sus correspondientes manifestaciones mediante recursos gráficos y/o narrativos impresos, favorecieron la circulación transnacional de teorías geológicas, prácticas geográficas y estrategias procedimentales. En dicha circulación, como se analizará a continuación, Sierra Nevada ocuparía un lugar privilegiado, cuyo conocimiento geográfico con rigurosidad científica asimilaría esta normalización del método del desplazamiento de la mirada desde la cumbre a lo largo de todo el siglo XIX y el primer cuarto de la centuria siguiente.

Simón de Rojas Clemente y Rubio fue el primer naturalista que subió a Sierra Nevada para llevar a cabo, entre 1804 y 1809, un trabajo sistemático de medición y nivelación de las cumbres, entre otras investigaciones. Su viaje a la Sierra formó parte del proyecto estatal para estudiar la vegetación silvestre y 
cultivada del país en el marco de los nuevos proyectos científicos promovidos por el Real Jardín Botánico de Madrid. Clemente y Rubio conocía muy bien las contribuciones científicas foráneas de su tiempo, concretamente las investigaciones en geología llevadas a cabo en Europa a finales del siglo XVIII. Se refirió a algunos fenómenos de la alta montaña observados por Ramond en el Pirineo, citó las teorías de científicos como Abraham Gottlob Werner y Déodat Gratet de Dolomieu, estuvo en contacto con Carlos de Gimbernat (quien investigaría en los Alpes), y fue también conocedor de las exploraciones de Saussure en la cordillera alpina (Capel Sáez, 2002; Clemente y Rubio, 2002)3. A través de la lectura de la obra del naturalista ginebrino - a quien citó con frecuencia en su obra-, se familiarizó con el método de la visión global panorámica, con las reflexiones sobre su relevancia y aplicación en terreno, y con su traslación a modelos de representación geográfica del paisaje. Además del referente de Saussure, Clemente y Rubio conoció los nuevos formatos perspectívicos foráneos, ya que estaba integrado en un ambiente científico nacional que había incorporado distintos modelos de representación de la montaña relacionados con estudios de carácter geográfico y geológico, como, por ejemplo, el formato del tour d'horizon, introducido unos años antes en las propuestas científicas españolas, con ejemplos como el de Cavanilles de 1793 (Mateu Bellés, 2008).

El conocimiento de estos antecedentes le permitió a Clemente y Rubio asimilar la visión panorámica como método a partir del encuentro físico con las cumbres nevadenses con el fin de revelar el orden topográfico y las alineaciones de los cordales de la Sierra. Haciéndose eco de las convicciones de sus pares europeos, como Saussure y Ramond, según los cuales una mirada integral a los componentes del conjunto paisajístico bastaba para desentrañar el caos que el trabajo de gabinete no elucidaba, Clemente y Rubio (2002) "[e]speraba que en la cumbre de Veleta satisfaría mi curiosidad impaciente" (p. 648). Así, recogió la hipótesis de Saussure, según la cual, como se indicó anteriormente, el estudio de las montañas era la única manera de acelerar el conocimiento de la teoría de la tierra, y declaró su objetivo de llevar a cabo la "clasificación y descripciones" de lo que él consideraba la "osamenta o el esqueleto del globo" (es decir, "las sierras") mediante la ascensión sistemática a las cumbres nevadenses para examinar su cordal principal (Clemente y Rubio, 2002, p. 95). De este modo, el científico español planteó una explicación de la naturaleza como conjunto sistemático de elementos relacionables al considerar los distintos componentes "como nexos del mismo cuerpo geográfico" en sus observaciones geognósticas desde lo alto del Veleta (Clemente y Rubio, 2002, p. 95). Asimismo, tomó como modelo narrativo de sus investigaciones la estructura del relato científico de Saussure — quien había presentado sus ascensiones a las cumbres alpinas en clave de expedición-, y organizó sus textos en "Itinerarios", acuñando información exacta sobre las estaciones, paradas, fechas y horarios de su itinerario en terreno por la montaña bética (Clemente y Rubio, 1863, p. 3; Clemente y Rubio, 2002).

Clemente y Rubio fue consciente de que el abordaje de tales objetivos ameritaba la aplicación de procedimientos metodológicos novedosos, importados de las últimas contribuciones geográficas foráneas. De esta forma, adoptó la utilización de la visión móvil y su traslado correspondiente a formas impresas a través de varios recursos de representación panorámica, como la écfrasis, los dibujos y los croquis, para cuya realización empleó instrumentos como la cámara oscura y el telescopio, ya utilizados en las investigaciones alpinas (Broc, 1991, p. 73; Capel Sáez, 2002, p. 45). Desde el Veleta y el Mulhacén, ofreció varias descripciones panorámicas del cordal de las altas cumbres serranas, aportando información sobre su orientación y la caracterización de su relieve, variables que solo pudo sistematizar mediante la aplicación de la mirada envolvente al conjunto de la montaña:

Desde el Puerto de Bacares se veían correr de N.O. 1/4 al Oeste a S.E. 1/4 al Este los Cerros con este orden: Veleta, los Machos, el de la Laguna de la Caldera, la Alcazaba, Mulhacén, Tajo Negro, sobre la Laguna de Bacares. (...) El Cerro de Mulhacén tiene su corte o tajo al N.N.O., como todos los demás, excepto el de los Machos y Veleta, que están cortados desde el punto de Sur hasta el de N.E., siendo el corte mucho más profundo desde el punto del Este al N.E. (Clemente y Rubio, 2002, p. 212).

3 Las dos obras de Rojas Clemente y Rubio citadas en este artículo datan de 1863 y 2002. Conviene aclarar que no son reediciones, sino obras que fueron publicadas una vez que su autor hubo fallecido en 1827. La obra de 1863, como se indica en la bibliografía, se trata de un "Trabajo ordenado conforme á los manuscritos del autor, por D. Miguel Colmeiro"; mientras que la obra de 2002, editada por Gil Albarracín, es una compilación de un gran conjunto de notas de trabajo del botánico (manuscritos que forman ocho volúmenes independientes y que se encuentran depositados en el Archivo del Real Jardín Botánico de Madrid), que vieron la luz, por vez primera, en dicho año. 
Durante sus trabajos de nivelación del Mulhacén, Clemente y Rubio realizó algunos perfiles panorámicos parciales de las cumbres de la Sierra (Figura 2). Estas ilustraciones informaban, en clave toponímica, de los elementos geográficos principales, y las notas del científico ofrecían una descripción topográfica para la comprensión del relieve, haciendo evidente su interés por la organización del cordal que su ojo en movimiento alcanzaba a discernir desde la posición privilegiada de la cumbre: "Vista de Mulhacén (...) desde la cumbre de Veleta. De c está perfectamente tajada la cumbre. Lo rojizo es nieve. a. Mulhacén. b. La Alcazaba. c. A su Oriente está la Caldera. nnn. Cuerda central que desde Mulhacén corre a Veleta" (Clemente y Rubio, 2002, p. 1095). Si en el caso de la célebre panorámica circular de Saussure era la línea del dibujo la que traducía la mirada integral móvil al conjunto del paisaje de la montaña, aquí la descripción sintética se convertía en el vehículo expresivo de comunicación de la visión racional científica sobre el esqueleto geográfico de la montaña.

Figura 2. Simón de Rojas Clemente y Rubio: Vista de la parte principal (septentrional) de Sierra Nevada, tomada desde la cumbre del Calar de Güéjar

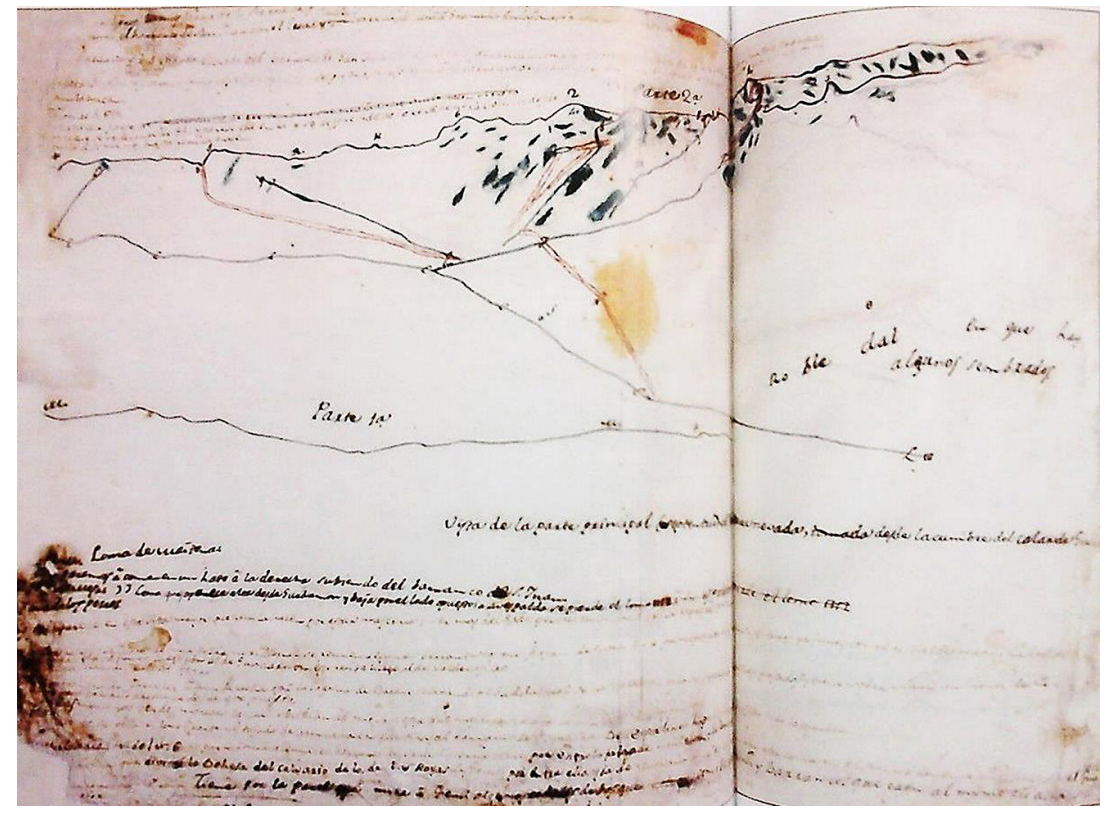

Fuente: Clemente y Rubio (2002)

\subsection{Juan Carandell: panoramas, retóricas y tours d'horizon en el estudio del "Montblanc de España”}

Más de un siglo después de la aportación de Clemente y Rubio al conocimiento geográfico de Sierra Nevada —además de otras importantes contribuciones de científicos de renombre internacional de la época, como Edmund Boissier y Moritz Willkomm-, el macizo siguió acaparando una notable atención en las ciencias geográficas españolas. Su orogenia, geomorfología y estructura tectónica marcaron las investigaciones sobre la montaña nevadense y el conjunto de los Sistemas Béticos llevadas a cabo por el geólogo y catedrático de Historia Natural Juan Carandell Pericay en el primer cuarto del siglo XX, dando como resultado un total de dieciséis obras sobre Sierra Nevada (López Ontiveros, 2006; López Ontiveros y Naranjo Ramírez, 2000; López Ontiveros, Naranjo Ramírez y García García, 2007). También en este caso, la transmisión del conocimiento previo acerca de los Alpes se hizo muy evidente. La aportación de Carandell a la geografía de su tiempo, como se verá, estuvo determinada por su amplio conocimiento de los métodos y las formas narrativas y de representación que habían sido (y aún estaban siendo) empleados en el discurso geográfico europeo sobre la alta montaña.

En sus estudios geomorfológicos, Carandell no dudó en tomar el referente alpino como modelo para su explicación de Sierra Nevada, patrón que se había normalizado en las distintas interpretaciones de los viajeros foráneos del siglo anterior (Cornejo Nieto, 2018). El geólogo trazó una serie de relaciones y analogías entre los Alpes y lo que, según él, debía llamarse "los Béticos", conceptualizando la Sierra como el "núcleo del Sistema Bético, de los Alpes andaluces" (cit. en López Ontiveros y Naranjo Ramírez, 2000, p. 288), y 
afirmando que "la gigantesca cúpula de la Sierra Nevada" constituía la masa más importante del relieve andaluz (Carandell Pericay, 1930, pp. 122, 124). En sus frecuentes comparaciones entre ambos sistemas montañosos, Carandell (1920) se lamentaba, sin embargo, del contraste entre la desigual y atípica morfología de la Sierra, con su "casi carencia de facies alpinas", y el "carácter grandioso de los Pirineos y los Alpes" (p. 47), ponderando las agrestes formas del relieve de estos últimos con la mayor suavidad del modelado de la Sierra (véase también Carandell Pericay, 1930, pp. 127-128). El razonamiento analógico de Carandell se completaba con un curioso apéndice al final de su escrito "La morfología de la Sierra Nevada; ensayo de su interpretación tectónica", en el que el autor, con el fin de evidenciar otras similitudes entre Sierra Nevada y los Alpes, presentó un "paralelo morfológico" entre el macizo y los "Alpes Transilvanos" (Cárpatos) apoyado en las tesis del geógrafo francés Emmanuel de Martonne, manifestando así su interés por poner sus trabajos en diálogo con el conocimiento geográfico europeo de su tiempo (Carandell Pericay, 1920, pp. 75-76).

En el XIV Congreso Geológico Internacional, celebrado en Granada en 1926, Carandell estableció definitivamente, según su criterio, la analogía de carácter geográfico y geológico entre las altas cumbres de Sierra Nevada, epítome de "los Béticos", y el macizo del Mont Blanc, paradigma de los Alpes. En su artículo "Sierra Nevada, Montblanc de España", publicado con motivo de la conferencia ofrecida en dicho evento, constató que "hablar de Sierra Nevada" equivalía a tratar el macizo "cual si fuera el Montblanc de España" (Carandell Pericay, 1926a, p. 66). Con ello, no solo reafirmó las comparaciones que ya había planteado en anteriores publicaciones, sino que propuso la identificación directa de los Béticos con los Alpes, utilizando como estrategia la extrapolación, en términos geomorfológicos, de la región montañosa de Andalucía oriental al centro del continente:

Mediante el uso del discurso analógico, "[v]an a ser esos Alpes majestuosos; ese Valle del Ródano; aquellas montañas que, constituyendo la que pudiéramos llamar Sierra Morena de la vecina Francia, toman los nombres de Cevennes; Morvan, Plangres, Cuesta de Oro; serán finalmente, el Lago de Ginebra y los ríos Ródano y Saona". (Carandell Pericay, 1926a, p. 68).

Seguidamente, mostró los paralelismos orogénicos y tectónicos de las dos cadenas montañosas y sus sierras adyacentes, llevando así "la comparación entre Andalucía Oriental y el centro de Europa a los rasgos estructurales" (Carandell Pericay, 1926a, p. 68), y presentando los materiales de las distintas fases orogénicas del macizo nevadense a fin de elaborar su analogía con los de la cordillera centroeuropea. Su ejercicio comparativo, además de comprender la formación rocosa de ambos sistemas, se extendió a todo el territorio que quedaba configurado por sus respectivos plegamientos. De esta manera, Carandell Pericay (1926a, p. 69) confrontó la vertiente sur de la Sierra, las Alpujarras, con la depresión meridional de los Alpes, encarnada por el Piamonte italiano, y señaló el paralelismo de las cortezas terrestres de ambas cordilleras, que se hunden hasta el Mediterráneo.

Además de adoptar el modelo explicativo alpino para el estudio de la Sierra, Carandell también se hizo eco del método de observación panorámica desde la cumbre, aplicando sus correspondientes tipologías de representación (panoramas y vistas circulares) para comunicar sus investigaciones. Fruto de esta importación metodológica, compuso varios dibujos panorámicos de la Sierra. Su artículo "La morfología de la Sierra Nevada; ensayo de su interpretación tectónica" incorporó dos láminas de este tipo: el Panorama total de la Sierra Nevada y el Panorama desde el Veleta. Esta última (Figura 3) le sirvió para mostrar uno de los argumentos del texto: el marcado contraste de las formas del relieve que modelan lo que él denominaba el macizo central metamórfico o "la sierra por excelencia" (Carandell Pericay, 1920, p. 47). Dentro de ese contraste, contemplado desde el tajo del Corral del Veleta, Carandell Pericay (1920) destacaba la "imponente y majestuosa" (p. 47) presencia de los "enormes escarpes verticales" (p. 56) que definen las caras norte de las mayores cumbres del cordal principal. Tras reconocer la "pesada monotonía" que presentaba la ascensión al Corral, la mirada envolvente y esclarecedora de Carandell, como Ramond en Pirineos o Saussure en los Alpes, le fue suficiente para desvelar el "gigantesco braquianticlinal" del pliegue-falla Mulhacén-Veleta, permitiéndole reconducir su relato: "la faz del relieve se transmuta por completo" (Carandell Pericay, 1920, p. 56). La estrategia discursiva del artículo se mostraba con claridad: basada en la explicación de la morfología del macizo a partir de la contraposición de sus dos formas principales del relieve —la suavidad de las lomas versus la verticalidad de los tajos-, Carandell Pericay (1920) presentaba el dibujo como modelo de representación complementario a tal explicación, mostrando los "dos tipos morfológicos que se dan en la Sierra Nevada: tipo vosgiense, relieve propio de montaña media; y tipo alpino, escarpado y ceñudo" (p. 57). Por tanto, mediante el recurso icónico-textual, el objetivo de Carandell parecía esclarecerse: otorgar relevancia al aspecto propiamente cordillerano, y, con ello, alpino, del macizo nevadense. 


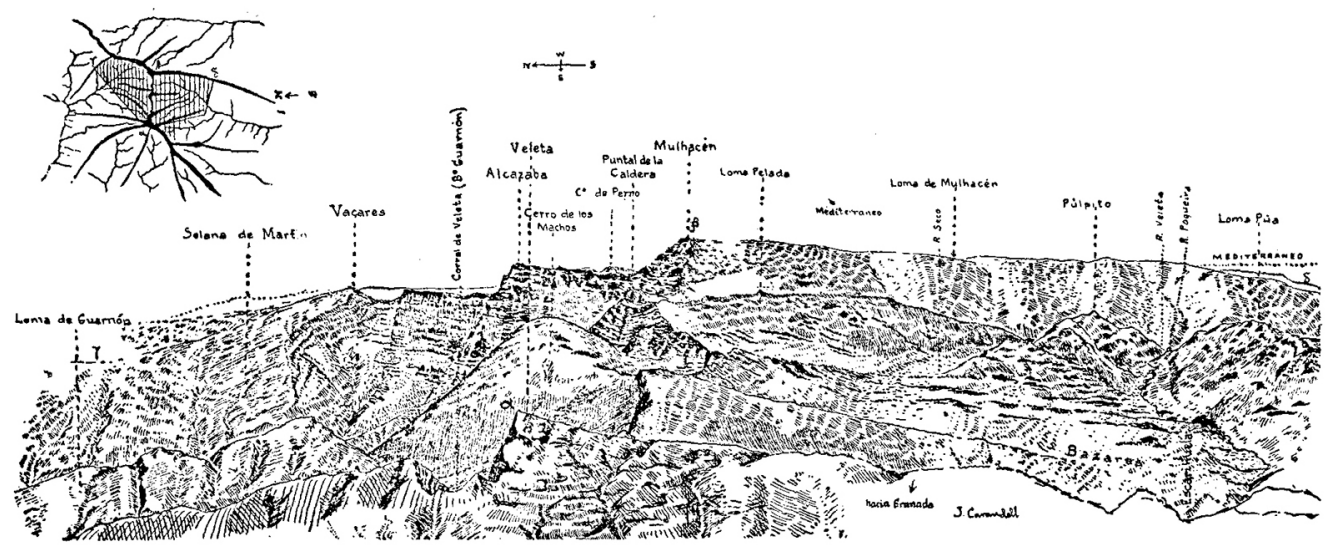

Fuente: Carandell Pericay (1920)

El Panorama total (Figura 4), tomado desde la Loma del Calvario, mostraba dos aspectos importantes. Por un lado, exponía gráficamente el cordal principal de las altas cumbres del macizo (hasta la Alcazaba en su parte oriental), enfatizadas por el sombreado de la técnica del dibujo, y, por otro, revelaba con claridad los profundos barrancos de la vertiente norte, fruto de la erosión glaciar, con la cuenca del Genil en primer término. De este modo, Carandell Pericay (1920) ratificaba gráficamente el carácter abrupto del relieve de la cara septentrional del macizo, subrayando, incluso, su singularidad, ya que, como afirmó en el texto, "no ya en España, quizá ni en los Alpes hay ejemplos más patentes" de la profundidad de las "recientes fracturas" desde aquel punto privilegiado que el geólogo supo relevar para la aplicación de la visión panorámica sobre la faz más alpina de la Sierra (p. 53).

Figura 4. Juan Carandell: Panorama total de la Sierra Nevada

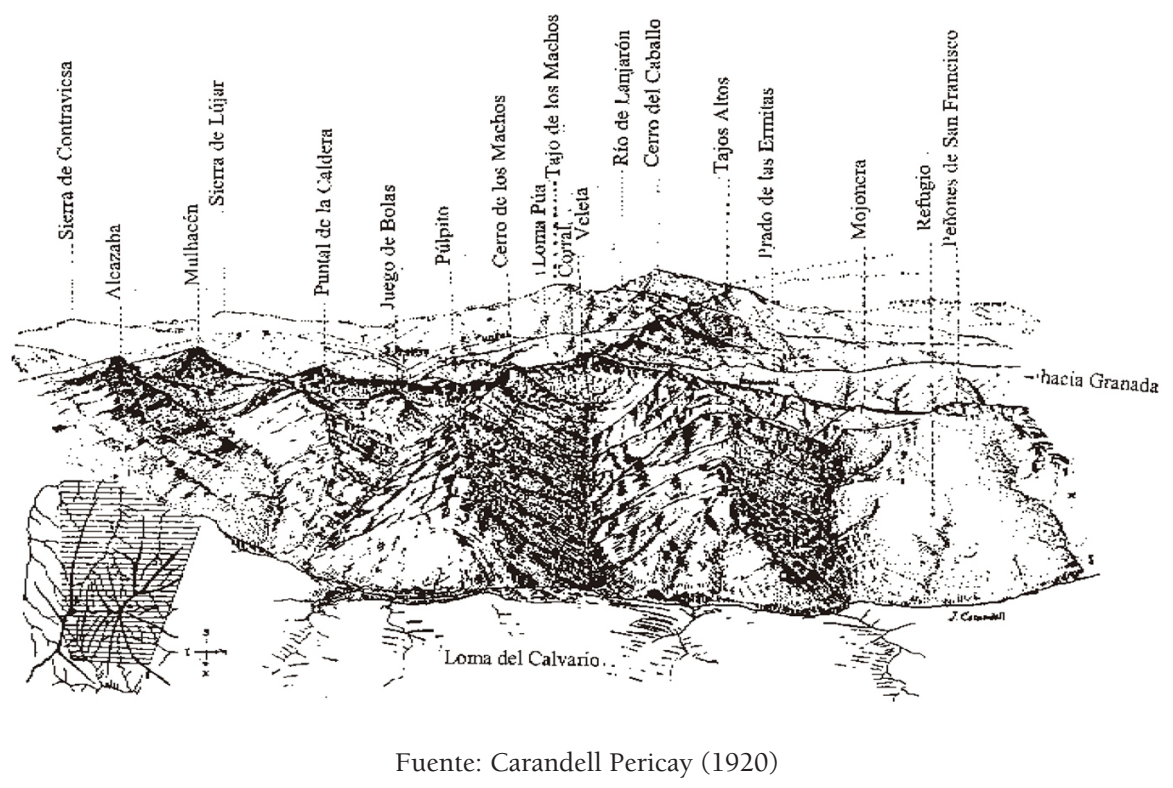

Entre el conjunto de sus panoramas, Carandell destacó la Panorámica de Sierra Nevada desde la Sierra de Cabra (Figura 5), una representación de la vertiente norte del cordal principal de Sierra Nevada desde las Sierras de Córdoba, dibujada y pintada a la acuarela.

La panorámica iba acompañada de un croquis en la parte inferior de la representación, que le sirvió a Carandell como recurso gráfico para señalar las distancias desde el punto de vista tomado hasta el Cerro del Caballo, en el extremo occidental del macizo, el Pico del Cuervo, en el extremo oriental (entre los 
cuales quedaba comprendido el cordal principal más elevado de Sierra Nevada), y el Picacho del Veleta, centrado en la imagen junto con el Mulhacén y la Alcazaba, como las tres cotas máximas del macizo. El croquis dejaba entrever la autoridad de la representación, indicando el foco de origen del observador soberano - el científico- y el control racional de la ejecución de su mirada panorámica sobre el territorio. En el punto de fuga de la composición, el marcado modelado glaciar de la cara norte contrastaba con la "serenidad de perfiles [del resto del macizo] verdaderamente inaudita" (Carandell Pericay, 1930, p. 123). Carandell utilizaba la autoridad de su mirada, situada estratégicamente en la Sierra de Cabra, para destacar la verticalidad del relieve, de reminiscencias alpinas, de las caras norte de las tres grandes cumbres nevadenses, la Alcazaba, el Mulhacén y el Veleta, que le servía al científico para demostrar su frecuente (y deseada) analogía con la cordillera centroeuropea. De este modo, sobre cualquier otra peculiaridad geográfica, acentuaba las concomitancias más evidentes con la alta montaña europea, subrayando, mediante la retórica, el aspecto más agreste de la Sierra (Carandell Pericay, 1920, pp. 53-54): “¿Quién sospechará que aquellos picos, de redondeado perfil, (...) se nos presentarán con una bravura inaudita cuando nos dispongamos a remontar la Sierra por otros puntos, o cuando se nos aparezcan, desconocidos, desde las distintas estaciones de nuestro itinerario?".

Figura 5. Juan Carandell: Panorámica de Sierra Nevada desde la Sierra de Cabra.
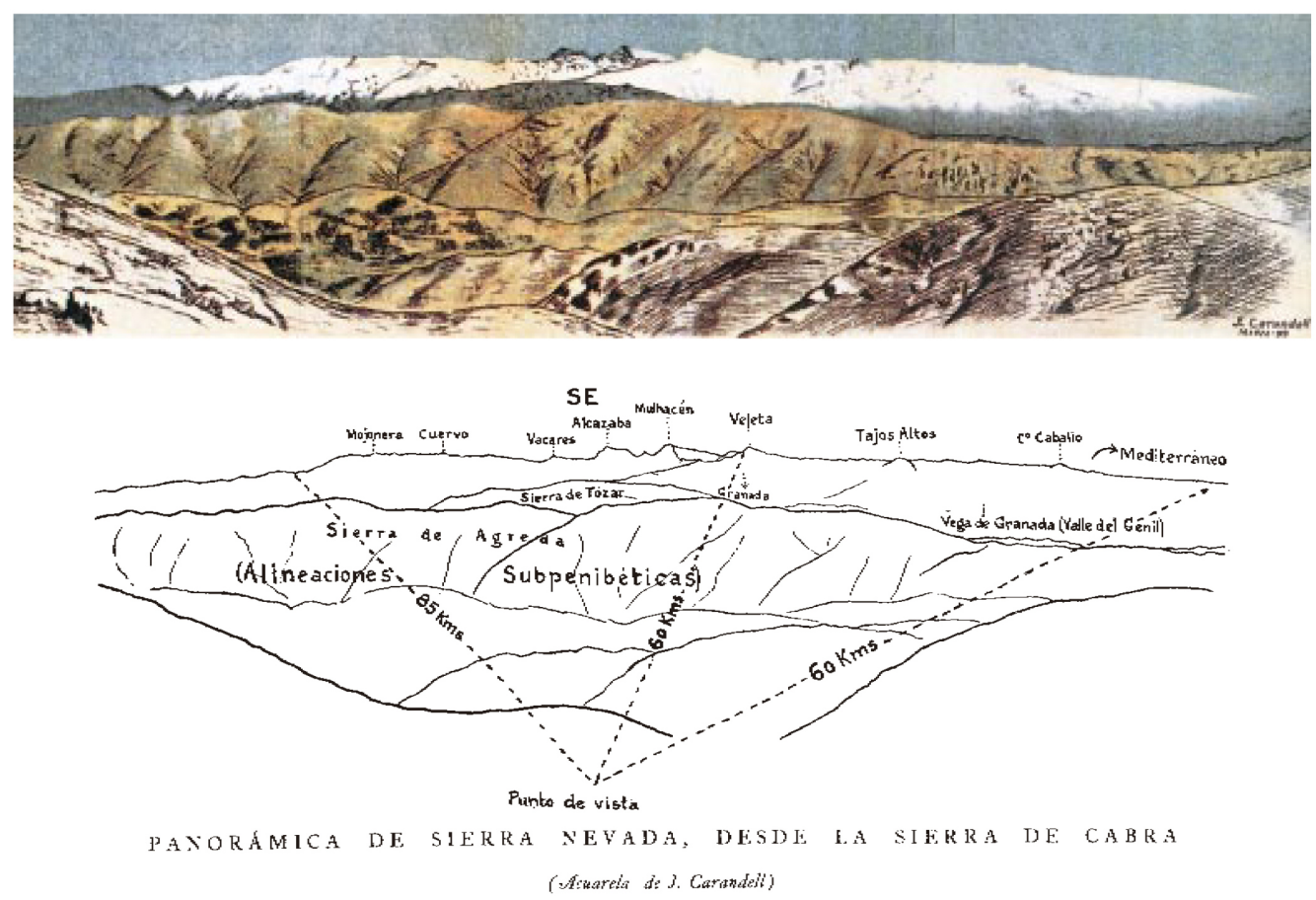

Fuente: Bernaldo de Quirós (1923)

En su conferencia pública del congreso mencionado, Carandell no solo reforzó el razonamiento analógico en su explicación, sino que también utilizó el recurso del tour d'horizon, manifestando su profundo conocimiento acerca de los formatos geográficos de representación utilizados en los estudios de los Alpes. Al igual que hiciera Saussure en sus Voyages, comunicó de manera explícita su preocupación por "fijar gráficamente la amplitud de los horizontes que desde el Veleta se divisan" (Carandell Pericay, 1926a, p. 66), como ya había quedado patente en sus publicaciones anteriores. En esta ocasión, sin embargo, en lugar de utilizarlo como imagen impresa, empleó la vuelta de horizonte desde el Picacho como recurso retórico comunicativo en el espacio de la presentación pública, al tiempo que proyectaba las imágenes ante la audiencia. Para la presentación de sus planteamientos visuales, Carandell (1926a) propuso "algo así como la cinematografía de un viaje desde Granada al Picacho" (p. 69) a fin de trasladar a los asistentes a la misma cumbre del Veleta. Así, mediante la herramienta del desplazamiento virtual a la cima de la montaña, acompañado de la proyección de unas vistas de la Sierra, Carandell invitaba a reflexionar, en un acto público de auténtica transmisión y comunicación del conocimiento geográfico, sobre las concomitancias entre los dos macizos. 
Una vez que hubo llevado al público a la cumbre del Veleta, Carandell (1926a) expuso el paralelismo entre el Montblanc y el Picacho utilizando el panorama circular y el método comparativo, para lo cual exhibió "el amplísimo horizonte copiado por mî", que proyectó "comparándolo con la vuelta de horizonte trazada por Helbronner desde el Montblanc francés" (p. 69). De este modo, el paralelismo entre un sistema y otro fue articulado y presentado visualmente al público a través de la captación visual comparada de los relieves de ambas cordilleras. Para ello, se sirvió primero del célebre tour d'horizon levantado por el geodesta francés. Situado visual (y virtualmente) sobre la cumbre de los Alpes, Carandell trasladó a los oyentes el relieve de Andalucía, identificando así un paisaje con otro:

Vais a ver la línea recta, suave, del borde de la Meseta francesa, homólogos de la Sierra Morena y Meseta españolas; veréis el lago de Ginebra, homólogo de la vega de Granada o de la llanura de Guadix; veréis los Alpes Marítimos, homólogos de la Contraviesa y la sierra de Lújar; veréis el Jura franco suizo, homólogo de nuestras sierras de Jaén, de Luque, de Alcalá y Priego. (Carandell Pericay, 1926b, p. 52).

Tras la proyección del panorama alpino de Helbronner, Carandell presentó al público su propio tour d'horizon desde el picacho del Veleta, en el que alternó la descripción pormenorizada del paisaje circular con sus propias impresiones subjetivas, referencias a acontecimientos históricos y textos literarios sobre las cumbres nevadenses. Si con la imagen del horizonte desde el Montblanc el geólogo evocaba los Sistemas Béticos y sus depresiones, ahora el proceso se invertía, recurriendo a la analogía presentada anteriormente:

¿No recordáis cómo desde el Montblanc veíamos la Cevennes, el Morvan, el Beaujolais, al Cuesta de

Oro? Pues traducid por Sierra de Córdoba, de Adamuz, de Montoro, de Andújar, de Bailén, esos nom-

bres franceses, y el paisaje justificará por sí mismo el por qué titulo esta conferencia: Sierra nevada, Montblanc de España. (Carandell Pericay, 1926b, pp. 55-56).

A pesar de la marcada referencia alpina en toda su explicación, Carandell se mostró consciente de los particularismos de Sierra Nevada y, por tanto, de sus diferencias fundamentales con su pretendido homólogo continental. En este sentido, recurrió a tres aspectos específicos del macizo en su argumentación. En primer lugar, subrayó su ubicación geográfica, estrategia que utilizó para otorgar a la montaña bética un elemento valorativo de unicidad, basado en su extraordinaria proximidad al mar, factor que evidenciaría su condición de alta montaña mediterránea distinta a la alta montaña centroeuropea. Carandell recogía así parte del conocimiento científico que se había generado en torno a Sierra Nevada a lo largo del siglo XIX, el cual ya había puesto de manifiesto, especialmente a través de la obra de Moritz Willkomm, las especificidades de la alta montaña nevadense en función de ciertos factores implicados en su geolocalización, y que escapaban del canon alpino. ${ }^{4}$ En sintonía con Willkomm, Carandell recalcaba, al hablar del Mulhacén y a pesar de la falta de uniformidad en las formas del relieve propiamente alpinas, no su excepcionalidad geomorfológica completa (salvo su cara norte), sino su ubicación en relación al espacio geográfico circundante: "a unos 45 [kilómetros] de la costa mediterránea, yérguese hasta cerca de tres kilómetros y medio el Mulhacén, pico culminante de la Sierra Nevada y máxima altura de la Península ibérica" (Carandell Pericay, 1920, p. 47). De este modo, según Carandell (1920) "[c]ompensa la casi carencia de facies alpina (...) la estrecha asociación del elemento terrestre con el marino (...) [ya que] agiganta aún más el relieve del ingente monolito andaluz" (p. 47); una relación de contraste que le otorgaba al macizo una singularidad geográfica y paisajística distinta del referente alpino.

En segundo lugar, Carandell recurrió a la evocación de la historia local como elemento diferenciador de Sierra Nevada, refiriéndose al macizo como parte integrante del relato histórico y geopolítico de la Granada islámica. En la conferencia, presentó el corredor del Genil como "el punto vulnerable de la región granadina en la historia política", ya que, según su interpretación, "por ahí debía venir, fatalmente, la contestación que las huestes cristianas dieron al reto de Muley Hacén, acabando por derrotar a Boabdil" (Carandell Pericay, 1926b, p. 54). Y, en tercer lugar, Carandell diferenció a la Sierra del modelo alpino a través de las visuales panorámicas del paisaje obtenidas desde la cumbre, una dimensión que, no en vano, también había sido señalada por Willkomm. ${ }^{5}$ Haciéndose eco de esta particularidad, al final de la

4 Según la idea de Willkomm, no había en la península Ibérica ni en todo el continente europeo otra zona geográfica que se pudiera parangonar con la de Granada en altitud, formación ni "respecto a la ubicación geográfica y el clima" (Willkomm, 1993, p. 53).

5 El botánico alemán ya había sido consciente de que, si bien "Sierra Nevada carece de grandiosos glaciares, de cimas cubiertas de nieve perpetua, de maravillosas cataratas, de umbrosos pinares y de lagos encantadores, (...) de los que presumen los Alpes", superaba, sin embargo "a todas las sierras europeas", no solo en la ubicación — como se indicó anteriormente—, sino también en "el panorama sobre el mar Mediterráneo a la costa y montañas africanas" (Willkomm, 1993, p. 265). 
conferencia Carandell Pericay (1926b) afirmó que "la vuelta del grandioso horizonte del Veleta, de ese horizonte cuyo radio es de más de doscientos setenta kilómetros", constituía no solo "el mayor de Europa después del Montblanc", sino también "el mayor de Europa en absoluto, porque Sierra Nevada tiene el Mediterráneo a treinta y cinco kilómetros, lo que no le sucede al Montblanc" (p. 57). Finalmente, si bien Carandell aprovechó su mirada global al macizo para explicar y comunicar algunos de los particularismos específicos de Sierra Nevada, su deseo por asimilar en su totalidad el referente alpino en su interpretación geográfica de la Sierra le hizo decantarse por su caracterización exógena al concluir que, "recordando que [la Sierra] fue árabe, parece querer ocultar dentro del níveo jaique que la envuelve, los tesoros de sus encantos alpinos" (Carandell Pericay, 1926a, p. 71).

\section{Discusión de resultados}

Para los naturalistas suizos del círculo de Ginebra, el método de la aplicación visual panorámica sobre la ordenación geográfica de la montaña implicó una nueva forma de examinar el paisaje a través de un "ojo exploratorio" en movimiento (Della Dora, 2007, p. 294) que, además, debía ir acompañado de la experiencia física y corpórea de la ascensión a la cumbre. Este método, al tiempo visual y fenomenológico, permitió llevar a cabo los primeros análisis empíricos rigurosos de la orografía de los conjuntos montañosos mediante la visión móvil integral, vehiculada por la razón y complementada con la precisión instrumental; una mirada que privilegiaba las interrelaciones de los componentes geográficos a fin de aprehender y ordenar la naturaleza "en términos de sistema" (Briffaud, 1994, p. 187).

La implementación de dicha metodología desencadenó la invención de modelos gráficos y recursos narrativos que dieran cuenta del sistema que se pretendía descifrar. Aunque no estuvieron exentos de importantes connotaciones subjetivas, estéticas y filosóficas (Billing, 2019; Klonk, 2003; Reichler, 2002; Stafford, 1984, p. 54), estos modelos y recursos, presentados en formatos panorámicos de representación y descripción del paisaje, aparecieron como una declaración metodológica y epistemológica de intenciones al poner de manifiesto la función cardinal, reveladora y legítima de la mirada autónoma del naturalista como una "expresión máxima de autoridad racional", epítome del "sujeto soberano" cartesiano frente al estudio controlado de la naturaleza (Della Dora, 2018, pp. 190, 204; véase también Hansen, 2013, pp. 58-60). Las imágenes y écfrasis panorámicas, deudoras de esta autonomía de la mirada, contribuyeron a legitimar un nuevo régimen de verdad geográfico articulado en torno a un modelo explicativo icónico-textual que integró dichos recursos en el relato científico. Se configuró así el paradigma referencial discursivo del estudio sistemático de la montaña en el contexto de la génesis del pensamiento geográfico de la modernidad.

Por tanto, las cumbres alpinas constituyeron, empleando la terminología de Latour (2001), auténticos "archivos" de altitud o bases de datos naturales del geógrafo, establecidos como "centros de cálculo" (p. 362) desde donde se difundieron sus postulados teóricos y metodológicos a otras investigaciones en curso en ámbitos montañosos periféricos. De este modo, la visión panorámica y sus modelos de representación circularon desde el "conjunto de circunstancias iniciales" del mundo científico ginebrino, donde la idea se incorporó al discurso y apareció en formas impresas (Said, 1991, pp. 226-227), hasta los Pirineos. El lenguaje de representación adoptado por Ramond, deudor de las aportaciones de Saussure, presentaba igualmente la montaña como materia "legible" y "penetrable" (Stafford, 1984, p. 285) gracias a la aplicación de este nuevo método. La visión panorámica y sus correspondientes expresiones, siguiendo a J. Secord (2004), demostraron su eficacia como herramientas y "convenciones de transmisión" (p. 661) de los avances del conocimiento geográfico sobre las cordilleras europeas, teniendo, por tanto, un papel protagónico en la "concepción normativa de la montaña" (Frolova, 2001, p. 166). En el contexto de esta normativización discursiva de la montaña y a la luz del análisis de las fuentes, es preciso discutir, desde el marco teórico presentado, las implicancias de la circulación del conocimiento geográfico de las cordilleras continentales hasta Sierra Nevada, cuya evidente transmisión encontró en el macizo, según los términos de Said (1991) y J. Secord (2004, p. 669), un espacio periférico de recepción de procedimientos metodológicos, formatos de representación y estrategias narrativas de origen foráneo, basados en la aplicación de la mirada panorámica en movimiento.

Las teorías de Clemente y Rubio sobre Sierra Nevada se sustentaron en dicha transferencia del conocimiento mediante la adopción de los métodos analizados de procedencia europea, basados en la aplicación operativa de la mirada panorámica sobre los cordales de Alpes y Pirineos tras la ascensión a las cumbres. 
Como Saussure desde la cima del Buet o Ramond en Monte Perdido, la perspectiva que se le abrió al botánico español desde la cumbre del Veleta le reveló su orden topográfico, reconociendo, visual y, sobre todo, epistemológicamente, la existencia de la alta montaña nevadense dentro del sistema normativo de conocimiento geográfico de las cumbres continentales en el horizonte cognoscitivo de la Ilustración. Con ello, otorgó a la Sierra un orden legible a través de unos recursos y estrategias icónico-textuales de origen foráneo, articulados en torno a la organización del relato bajo una estructura expedicionaria de encuentro inmersivo con la montaña y a las representaciones gráficas. Estas últimas, elaboradas como croquis con anotaciones añadidas, fueron el resultado de lo que Latour (2001) ha denominado una "operación de traducción" (p. 120) de teorías y métodos exógenos a la realidad de la montaña nevadense, los cuales, desde el centro epistemológico ginebrino, se difundieron a las ciencias geográficas españolas.

Estos préstamos se vieron enriquecidos por el diálogo que Clemente y Rubio estableció conscientemente con las producciones científicas europeas de su tiempo, contribuyendo a la consolidación de "circuitos" de transmisión del conocimiento a través de estos "encuentros hermenéuticos" entre hipótesis, teorías y herramientas metodológicas propuestas por diferentes autores de la época (Secord, A., 2011, p. 285; Livingstone, 2005, p. 392). En consecuencia, a razón de lo que Said (1991) llama un "conjunto de condiciones de aceptación" y "procesos de institucionalización” locales (p. 226), que fueron posibilitados en este caso por el Real Jardín Botánico de Madrid, Clemente y Rubio protagonizó un proceso de construcción y legitimación de un nuevo discurso geográfico en el espacio de Sierra Nevada y en el contexto de la reciente institucionalización de las ciencias naturales en la España de su tiempo. El naturalista mostró así una montaña inteligible en términos geográficos, hasta entonces carente de representación científica, conceptualizando el macizo como un sistema articulado por la interrelación lógica de sus elementos, y consolidándolo como un espacio de recepción, producción y, desde entonces, transmisión del conocimiento geográfico europeo de la alta montaña.

Clemente y Rubio inauguró la genealogía de interpretaciones geográficas de la Sierra que sería completada por científicos como Boissier, Willkomm y, más tarde, Carandell, iniciando un proceso histórico de asimilación y extrapolación del referente alpino al análisis del macizo y la correspondiente construcción de su relato geográfico. Carandell llevó esta extrapolación a sus máximas consecuencias al proponer la "traducción de un lugar [Alpes] a otro [Sierra Nevada]" (Duncan y Gregory, 2010, p. 4), traducción que en su caso tendría un sentido bidireccional al optar por la identificación entre ambos sistemas y trasladar, en una operación analógica, el ordenamiento geográfico de una montaña a la otra. Si, según Duncan y Gregory (2010), los procesos de traducción, lejos de ser neutrales, están "atravesados por relaciones de poder y de deseo" (p. 5), se desprende que la traducción acometida por Carandell estuvo impregnada de su propio afán por conceptualizar el macizo en términos estrictamente alpinos, para lo cual utilizó un conjunto bien elaborado de herramientas retóricas e icónico-textuales, resultado de la observación panorámica, como estrategia de representación de aquellos elementos geográficos del macizo que se ajustaban a la idea normativa y hegemónica de la alta montaña, encarnada por el canon alpino.

En este sentido, los recursos gráficos, las técnicas narrativas y las herramientas retóricas empleadas por Carandell formaron parte de su propia "estrategia interpretativa" (Keighren y Withers, 2012, p. 12) de la geografía bética con el objetivo, por un lado, de "demostrar la credibilidad autoral" de su propio discurso (Keighren y Withers, 2012, p. 13), y, por otro, de dotar de legitimación al macizo nevadense como objeto de análisis geográfico en el contexto del sistema de conocimiento normalizado de la alta montaña continental. En esta estrategia de legitimación, Carandell estudió, representó y comunicó la geografía de la Sierra recurriendo a términos y procedimientos exógenos, regulados y autorizados por las ciencias geográficas internacionales y sustentados en la soberanía racional de la visión panorámica. Por tanto, este proceso de traducción del conocimiento y esta estrategia de interpretación geográfica le permitió a Carandell sistematizar un régimen de verdad geográfico sobre la Sierra, validado por los preceptos normativos emanados del conocimiento científico de origen alpino, y consolidando así la contribución anterior de Clemente y Rubio.

Por consiguiente, se infiere que el canon de la alta montaña alpina actuó como mediador en las interpretaciones geográficas de Sierra Nevada a lo largo del siglo XIX y el primer cuarto del siglo XX, constatando que se produjeron continuos y cada vez más elaborados "actos de traducción" (Livingstone, 2003, p. 11; Duncan y Gregory, 2010, p. 4) de teorías y procedimientos importados desde el centro alpino a la periferia nevadense. Se trataron, por tanto, de procesos de traducción epistemológica que cristalizaron en la sistematización científica de una montaña "otra" a partir de criterios, categorizaciones y 
representaciones previamente legitimados en geografías foráneas, ajenos, por tanto, a las particularidades geográficas locales. Como resultado, se desprende que Sierra Nevada, en la medida que constituyó lo que se podría denominar una montaña periférica de recepción del conocimiento geográfico normativo de la alta montaña europea, fue producto de una operación interpretativa de dimensiones científicoculturales en función de modelos exógenos, hecho que derivó en la frecuente omisión de, o falta rigurosa de atención a las singularidades del macizo y, por ello, en la desnaturalización de su propia geograficidad.

Sin embargo, dicha recepción y extrapolación del conocimiento, lejos de constituir una mera importación, implicó, en el caso particular de Carandell, una voluntad de "reconstrucción" de las ideas y el discurso originales (Cosgrove y Della Dora, 2008, p. 4). En este sentido, como indica Livingstone (2003), las condiciones locales del espacio geográfico de recepción -en este caso los particularismos del macizo- "limitaron el discurso" (p. 7) importado, afectando en esta transmisión y reapropiación del relato hegemónico de la montaña. A partir de estas limitaciones, surgieron "apropiaciones creativas" distintas de la teoría original (Said, 1991, p. 226) en el seno de la interpretación científica carandelliana de la montaña nevadense. Del análisis de las fuentes, se desprende que el proceso de traducción del conocimiento llevado a cabo por Carandell se vio interferido por una "compleja dialéctica entre el reconocimiento y la recuperación de la diferencia" (Duncan y Gregory, 2010, p. 4), representada por las características específicas de Sierra Nevada y puestas de relevancia en interpretaciones científicas anteriores (especialmente la de Willkomm), que Carandell supo recoger en sus publicaciones y conferencias. Estas singularidades, ya indicadas, funcionaron como aspectos distintivos de la geografía bética que, más allá de marcar la diferencia con las cordilleras continentales de referencia, provocaron una cierta reformulación de las teorías exógenas. Se produjo, por tanto, una reinterpretación situada del discurso, tanto geográficamente, en la medida que visibilizó las características propias del macizo, como epistemológicamente, en tanto que estuvo determinada por el "encuentro hermenéutico" (Livingstone, 2005, p. 392) entre las aportaciones de Carandell y los textos científicos nevadenses. Carandell integró así las anteriores contribuciones de la genealogía del conocimiento acerca de Sierra Nevada en el relato canónico alpino de la alta montaña a través de un diálogo situado que hizo de la montaña bética un espacio de "hibridación textual" en el que diversos textos, interpretaciones y contenidos se trabaron de forma indiscriminada (Livingstone, 2005, p. 393; Withers y Livingstone, 2011, p. 11).

Se concluye que Sierra Nevada, conceptualizada en gran medida como una montaña de recepción, se alzó también, paulatinamente, como un espacio geográfico y epistemológico complejo de reinterpretación hermenéutica del discurso hegemónico de la alta montaña continental. Por consiguiente, se infiere que el relato geográfico moderno de Sierra Nevada —al cual contribuyeron Rojas Clemente y Rubio y Carandell en diferentes momentos de la modernidad - ha oscilado entre la pretendida universalidad de un régimen de verdad canónico en torno a la alta montaña europea y el progresivo reconocimiento de una identidad geográfica diferente que se correspondiera con las marcadas singularidades del macizo. Esta identidad propia iría ocupando una relevancia cada vez más significativa a lo largo de las décadas siguientes en la construcción de un conocimiento geográfico situado que diera cuenta de la complejidad de Sierra Nevada como un macizo de alta montaña singular, condicionado por su ubicación en un sector de influencia climática mediterránea y subtropical, su pasado histórico, la mutabilidad de su morfología y, finalmente, el vasto y luminoso panorama apreciable desde sus cumbres.

\section{Conclusiones}

La conceptualización geográfica de las cordilleras occidentales del continente europeo tuvo una dimensión relacional, tratándose de un conocimiento global construido en base al diálogo entre teorías, métodos, narrativas y formas de representación, todos ellos componentes de una cultura científica y visual comunes que circularon en el tiempo y en el espacio a lo largo de la modernidad. La transmisión y las imbricaciones de estas ideas y representaciones fueron fundamentales para pensar en el discurso geográfico moderno de Sierra Nevada como resultado del fenómeno de la circulación del conocimiento. En este sentido, las obras de Rojas Clemente y Carandell han de verse, por un lado, como parte de estos intercambios de naturaleza científica y cultural, y, por otro, como integrantes de una genealogía del saber geográfico nevadense y europeo acerca de la alta montaña, participando en la consolidación del estudio de las cordilleras continentales y contribuyendo al reconocimiento y la transmisión del discurso a través de su producción impresa. 
Considerando esta movilidad intelectual, el artículo ha abordado la historia del conocimiento de Sierra Nevada desde una perspectiva interrelacional dentro del contexto de la interpretación geográfica de la alta montaña en Europa occidental. De este modo, ha mostrado cómo la producción geográfica moderna en torno al macizo se ha ido conformando a partir de las continuas interacciones entre las ideas, vertidas en textos e imágenes tanto importados como producidos en el espacio local del macizo. Lejos de presentar un enfoque histórico aislado o autorreferencial de la montaña basado en distintas excepcionalidades, el presente trabajo ha problematizado la Sierra como un macizo cuya historia geográfica fue configurada a partir de continuos diálogos transnacionales con otras geografías de montaña continentales. Así, ha dado cuenta de la tensión entre lo global del fenómeno del encuentro científico con la montaña y lo local de sus respuestas situadas en un macizo cuya singularidad geográfica no fue debidamente apreciada hasta bien entrado el siglo XX. Asimismo, ha propuesto una lectura interpretativa de la Sierra como una montaña compleja, dotada de una discursividad e historicidad heterogéneas, idónea para el estudio de las geografías de recepción e interpretación de las ciencias geográficas europeas, reivindicándola así como un nexo importante de transmisión internacional de las ciencias geográficas.

En suma, el presente trabajo pretende constituir una contribución al estudio de la interpretación científica y cultural del macizo de Sierra Nevada como parte fundamental de la construcción discursiva de las geografías de montaña del continente europeo. Privilegiando una perspectiva histórico-hermenéutica, el artículo se inscribe así en aquellas investigaciones internacionales que han planteado enfoques complejos, dialogantes y multidireccionales entre los distintos aspectos (globales y locales) que forman parte del fenómeno de la interpretación de la montaña, y, con ello, abre la vía para el fortalecimiento de una mirada novedosa en el análisis de los sistemas montañosos peninsulares como importantes centros de intercambio de conocimiento. Conscientes de las limitaciones que supone el estudio de las zonas de alta montaña de Europa occidental en la medida en que la investigación queda circunscrita a unos métodos, discursos y representaciones propias del pensamiento moderno eurocéntrico, se trabaja actualmente en un tipo de cordillera extracontinental — concretamente en el centro-sur de Chile- a fin de explorar saberes, cosmovisiones e interpretaciones otras que permitan extender el tópico en el ámbito académico de una manera más plural, atendiendo así a la heterogeneidad, las diferencias y la pluriversalidad que ofrecen las geografías histórico-culturales de la montaña.

\section{Referencias}

Acín Fanlo, J. L. y Lampre Vitaller, F. (coords.) (2002). Aragón, un país de montañas. Zaragoza: Prames.

Anderson, B. (2020). Cities, Mountains and Being Modern in fin-de-siècle England and Germany. London: Palgrave Macmillan. https://doi.org/10.1057/978-1-137-54000-3

Armiero, M. (2011). A Rugged Nation: Mountains and the Making of Modern Italy. Isle of Harris: White Horse Press.

Beattie, A. (2006). The Alps: A Cultural History. Oxford: Oxford University Press.

Berdoulay, V., \& Saule-Sorbé, H. (1998). La mobilité du regard et son instrumentalisation. Franz Schrader à la croisée de l'art et de la science. Finisterra, XXXIII, 65, 39-50.

Bernaldo de Quirós, C. (1923). Sierra Nevada. Madrid: Comisaría Regia del Turismo y Cultura Artística.

Bigg, C. (2007). The panorama, or la Nature a coup d'oeil. En E. Fiorentini (Ed.), Observing NatureRepresenting Experience. The Osmotic Dynamics of Romanticism, 1800-1850 (pp. 73-95). Berlin: Reimer.

Bigg, C., Aubin, D., \& Felsch, P. (2009). Introduction: the laboratory of Nature-Science in the mountains. Science in Context, 22(3), 311-321. https://doi.org/10.1017/S0269889709990020

Billing, B. (2019). Circular visions: Viewing the world from above in the late eighteenth century. Journal of Historical Geography, 63, 61-72. https://doi.org/10.1016/j.jhg.2018.10.005

Boissier, E. P. (1839). Voyage botanique dans le midi de l'Espagne pendant l'anne 1837: Vol. Tome I. Narration et géographie botanique. Paris: Gide et Cie.

Briffaud, S. (1994). Naissance d'un paysage. La montagne pyrénéenne à la croisée des regards (XVIIe-XIXe siècles). Toulouse : AGM, Université de Toulouse II.

Broc, N. (1991). Les montagnes au siècle des lumières. Perception et représentation. Paris : Comité des Travaux Historiques et Scientifiques. 
Capel Sáez, H. (2002). El viaje científico andaluz de Simón de Rojas Clemente Rubio: de la historia natural a la geografía. En A. Gil Albarracín (Ed.), Viaje a Andalucía: «Historia natural del reino de Granada» (1804-1809) (pp. 17-46). Almería: Griselda Bonet Girabet.

Capell Brooke, Sir A. de. (1831). Sketches in Spain and Morocco. 2 vols. London: Henry Colburn and Richard Bentley.

Carandell Pericay, J. (1920). La morfología de la Sierra Nevada; ensayo de su interpretación tectónica. Revista de la Real Academia de Ciencias Exactas, Físicas y Naturales de Madrid, IX, 43-76.

Carandell Pericay, J. (1926a). Sierra Nevada, Montblanc de España. Reflejos, Julio, 65-71.

Carandell Pericay, J. (1926b). Sierra Nevada, Montblanc de España. Reflejos, Agosto, 51-57.

Carandell Pericay, J. (1930). Andalucía: Ensayo geográfico. Boletín de la Real Academia de Córdoba, 27 , 113-131.

Charlesworth, M. (2010). Landscape and Vision in Nineteenth-Century Britain and France. Surrey, England; Burlington, USA: Ashgate.

Clemente y Rubio, S. de R. (1863). Tentativa sobre la Liquenología geográfica de Andalucía, por D. Simón de Rojas Clemente. Trabajo ordenado conforme á los manuscritos del autor, por D. Miguel Colmeiro. Revista de los Progresos de las Ciencias, 14(1), 3-22.

Clemente y Rubio, S. de R. (2002). Viaje a Andalucía: «Historia natural del reino de Granada» (1804-1809) (A. Gil Albarracín, Ed.). Almería: Griselda Bonet Girabet.

Colley, A. C. (2010). Victorians in the Mountains: Sinking the Sublime. Surrey, England; Burlington, USA: Ashgate.

Comment, B. (2002). The Panorama. London: Reaktion Books.

Cornejo Nieto, C. (2015). La circulación del conocimiento en la creación del discurso geográfico de Sierra Nevada en el s. XIX. Cuadernos de Investigación Geográfica 41(1), 231-248. https://doi.org/10.18172/ cig. 2638

Cornejo Nieto, C. (2018). Representing the landscape of the Sierra Nevada (Granada): a 'translated' mountain of reception of the nineteenth-century Alpine geographical imaginations. En C. Kakalis \& E. Goetsch (Eds.), Mountains, Mobilities and Movement (pp. 213-235). London: Palgrave Macmillan. https://doi.org/10.1057/978-1-137-58635-3_11

Cosgrove, D., \& della Dora, V. (Eds.). (2008). High Places: Cultural Geographies of Mountains, Ice and Science. London: IB Tauris. https://doi.org/10.5040/9780755620357

Crary, J. (1990). Techniques of the Observer: On Vision and Modernity in the Nineteenth Century. Cambridge (Ma): MIT Press.

Curry, H. A., Jardine, N., Secord, J. A., \& Spary, E. C. (Eds.). (2018). Worlds of Natural History. Cambridge: Cambridge University Press. https://doi.org/10.1017/9781108225229

Debarbieux, B., \& Rudaz, G. (2015). The Mountain: A Political History from the Enlightenment to the Present. Chicago: The University of Chicago Press. https://doi.org/10.7208/chicago/9780226031255.001.0001

Della Dora, V. (2007). Putting the world into a box: a geography of nineteenth-century «travelling landscapes». Geografiska Annaler: Series B, 89(4), 287-306. https://doi.org/10.1111/j.1468$\underline{0467.2007 .00262 . \mathrm{x}}$

Della Dora, V. (2011). Imagining Mount Athos: Visions of a holy place from Homer to World War II. Charlottesville (Va): University of Virginia Press.

Della Dora, V. (2016). Mountain: Nature and Culture. London: Reaktion Books.

Della Dora, V. (2018). Mountains as a way of seeing: from Mount of Temptation to Mont Blanc. En C. Kakalis \& E. Goetsch (Eds.), Mountains, Mobilities and Movement (pp. 189-211). London: Palgrave Macmillan. https://doi.org/10.1057/978-1-137-58635-3_10

Duncan, J., \& Gregory, D. (Eds.). (2010). Writes of Passage. Reading Travel Writing. London: Routledge.

Frolova, M. (2001). La représentation et la connaissance des montagnes du monde: Pyrénées et Caucase au filtre du modèle alpin. Revue de Géographie Alpine, 89(4), 159-172. https://doi.org/10.3406/ rga.2001.3063 
Frolova, M. (2006). Les paysages du Caucase: Invention d’une montagne. París: CTHS.

Gómez Ortiz, A., \& Plana Castellví, J. A. (2006). La pequeña Edad del Hielo en Sierra Nevada a partir de los escritos de la época (siglos XVIII y XIX) y relaciones con el progreso de la geografía física y geomorfología española. Boletín de la Asociación de Geógrafos Españoles, 42, 71-98.

Gómez Ortiz, A., Milheiro Santos, B., \& Serrano Giné, D. (2008). Nieves, hielos y aguas en los paisajes de Sierra Nevada: El interés de la información gráfica de los libros de época. Cuadernos de Investigación Geográfica, 34, 101-118. https://doi.org/10.18172/cig.1209

Gómez-Ortiz, A., Palacios, D., Schulte, L., Salvador-Franch, F., \& Plana-Castellví, J. A. (2009). Evidences from historical documents of landscape evolution after Little Ice Age of a Mediterranean high mountain area, Sierra Nevada, Spain (Eighteenth to Twentieth centuries). Geografiska Annaler. Series A, 91(4), 279-289. https://doi.org/10.1111/j.1468-0459.2009.00370.x

Guilhot, N. (2005). Histoire d'une parenthèse cartographique. Les Alpes du nord dans la cartographie topographique française aux 19 e et 20esiècles. Lyon : Université Lyon II-Lumiere.

Hansen, P. (2013). The Summits of Modern Man: Mountaineering after the Enlightenment. Cambridge (Ma): Harvard University Press. https://doi.org/10.4159/harvard.9780674074521

Jardine, N., Spary, E. C., \& Secord, J. A. (Eds.). (1996). Cultures of Natural History. Cambridge: Cambridge University Press.

Jiménez Olivencia, Y., Porcel Rodríguez, L., \& Caballero Calvo, A. (2015). Medio siglo en la evolución de los paisajes naturales y agrarios de Sierra Nevada (España). Boletín de la Asociación de Geógrafos Españoles, 68, 205-232. https://doi.org/10.21138/bage.1859

Kakalis, C. \& Goetsch, E. (Eds.). (2018). Mountains, Mobilities and Movement. London: Palgrave Macmillan. https://doi.org/10.1057/978-1-137-58635-3

Keighren, I. \& Withers, Ch. (2012). The spectacular and the sacred: narrating landscape in works of travel. Cultural Geographies, 19(1), 11-30. https://doi.org/10.1177/1474474010393661

Klonk, C. (2003). Science, art, and the representation of the natural world. En R. Porter (Ed.), EighteenthCentury Science (pp. 584-617). Cambridge: Cambridge University Press. https://doi.org/10.1017/ CHOL9780521572439.026

Korenjak, M. (2017). Why mountains matter: early modern roots of a modern notion. Renaissance Quarterly, 70(1), 179-219. https://doi.org/10.1086/691833

Latour, B. (2001). La esperanza de Pandora: Ensayos sobre la realidad de los estudios de la ciencia. Barcelona: Gedisa.

Livingstone, D. (2003). Putting Science in Its Place: Geographies of Scientific Knowledge. Chicago: University of Chicago Press. https://doi.org/10.7208/chicago/9780226487243.001.0001

Livingstone, D. (2005). Science, text and space: thoughts on the geography of reading. Transactions of the Institute of British Geographers, 30(4), 391-401. https://doi.org/10.1111/j.1475-5661.2005.00179.x

López Ontiveros, A. (2006). El relieve de Andalucía en la obra gráfica de Juan Carandell Pericay. En N. Ortega Cantero (Ed.), Imágenes del paisaje (pp. 273-304). Madrid: Universidad Autónoma de Madrid.

López Ontiveros, A., \& Naranjo Ramírez, J. (2000). Juan Carandell Pericay (1893-1937) y Sierra Nevada. Cuadernos Geográficos de la Universidad de Granada, 30, 281-324.

López Ontiveros, A., Naranjo Ramírez, J., \& García García, J. (2007). Vida y obra del geólogo y geógrafo Juan Carandell Pericay, 1893-1937. Córdoba: Universidad de Córdoba.

Martínez de Pisón, E. (2000). Imagen de la naturaleza de las montañas. En C. Sanz Herráiz \& E. Martínez de Pisón (Eds.), Estudios sobre el paisaje (pp. 15-54). Madrid: Universidad Autónoma de Madrid.

Martínez de Pisón, E. (2004). El paisaje de montaña. La formación de un canon natural del paisajismo moderno. En N. Ortega Cantero (Ed.), Naturaleza y cultura del paisaje (pp. 53-121). Madrid: Fundación Duques de Soria y Universidad Autónoma de Madrid.

Mateu Bellés, J. (2008). Descubrimiento científico del paisaje. En J. Mateu Bellés \& M. Nieto Salvatierra (Eds.), Retorno al paisaje. El saber filosófico, cultural y científico del paisaje en España (pp. 347-387). Valencia: EVREN. 
Mathieu, J. (2009). History of the Alps (1500-1900): Environment, Development, and Society. Morgantown: West Virginia University Pres.

Moraldo, D. (2013). Gender relations in French and British mountaineering. Journal of Alpine Research | Revue de Géographie Alpine, 101(1). https://doi.org/10.4000/rga.2027

Naranjo Ramírez, J., \& López Ontiveros, A. (2011). La obra gráfica de Juan Carandell Pericay sobre Cataluña. Scripta Nova. Revista Electrónica de Geografía y Ciencias Sociales [En línea], XV(363). http:// www.ub.es/geocrit/sn/sn-363.htm

Nicolson, M. H. (1963). Mountain Gloom and Mountain Glory. The Development of the Aesthetics of the Infinite. New York: W. W. Norton and Company.

Nogué, J. (2005). Nacionalismo, territorio y paisaje en Cataluña. En N. Ortega Cantero (Ed.), Paisaje, memoria histórica e identidad nacional (pp. 147-169). Madrid: Fundación Duques de Soria y Universidad Autónoma de Madrid.

Nogué, J. \& Vicente, J. (2004). Landscape and national identity in Catalonia. Political Geography, 23(2), 113-132. https://doi.org/10.1016/j.polgeo.2003.09.005

Oettermann, S. (1997). The Panorama: History of a Mass Medium. New York: Zone Books.

Ortega Cantero, N. (2001). Paisaje y excursiones: Francisco Giner, la Institución Libre de Enseñanza y la Sierra de Guadarrama. Madrid: Raíces.

Ortega Cantero, N. (Ed.). (2005). Paisaje, memoria histórica e identidad nacional. Madrid: Fundación Duques de Soria y Universidad Autónoma de Madrid.

Ortega Cantero, N. (2012). Naturaleza, cultura y símbolo: La imagen de la montaña de Peñalara en el paisajismo español moderno. Cuadernos Geográficos de la Universidad de Granada, 51, 96-113.

Ortega Cantero, N. \& García Álvarez, J. (2009). Paisajes y lugares de memoria: Covadonga y El Paular. En N. Ortega Cantero \& E. Martínez de Pisón (Eds.), Los valores del paisaje (pp. 45-94). Madrid: Fundación Duques de Soria y Universidad Autónoma de Madrid.

Platt, J. P., Behr, W. M., Johanesen, K., \& Williams, J. R. (2013). The Betic-Rif Arc and its orogenic hinterland: a review. Annual Review of Earth and Planetary Sciences, 41(1), 313-357. https://doi. org/10.1146/annurev-earth-050212-123951

Ramond de Carbonnières, L. (1789). Observations faites dans les Pyrénées, pour servir de suite à des observations sur les Alpes, insérées dans une traduction des Lettres de W Coxe, sur la Suisse. Paris : Chez Belin.

Ramond de Carbonnières, L. (1801). Voyages au Mont-Perdu et dans la partie adjacente des Hautes-Pyrénées. Paris : Chez Belin.

Reichler, C. (2002). La découverte des Alpes et la question du paysage. Genève : Georg.

Ring, J. (2000). How the English Made the Alps. London: Murray.

Roma i Casanovas, F. (2004). Del Paradís a la Nació. La muntanya a Catalunya. Segles XV-XX. Valls: Cossetánia.

Rose, G. (2001). Visual Methodologies: An Introduction to the Interpretation of Visual Materials. London: SAGE.

Said, E. W. (1991). Traveling theory. En The World, the Text and the Critic (pp. 226-247). London: Vintage.

Saule-Sorbé, H. (2004). En torno a algunas «orografías» realizadas por Franz Schrader en los Pirineos españoles. Ería, 64-65, 207-220.

Saussure, H. B. de. (1779). Voyages dans les Alpes: Précédés d'un essai sur l'histoire naturelle des environs de Genève. T. I y III. Genève: Chez Samuel Fauche et Louis Fauche-Borel. https://doi.org/10.5962/bhl. title. 126330

Saussure, H. B. de. (1787). Voyages dans les Alpes: Précédés d’un essai sur l'histoire naturelle des environs de Genève. T. I y II. Genève: Chez Barde, Manget \& Compagnie.

Secord, A. (2011). Pressed into service: specimens, space, and seeing in botanical practice. In Ch. Withers \& D. Livingstone (Eds.), Geographies of Nineteenth-Century Science (pp. 283-310). Chicago: The University of Chicago Press. https://doi.org/10.7208/chicago/9780226487298.003.0012 
Secord, J. (2004). Knowledge in transit. Isis, 95(4), 654-672. https://doi.org/10.1086/430657

Speich, D. (2009). Mountains made in Switzerland: facts and concerns in nineteenth-century cartography. Science in Context, 22(3), 387-408. https://doi.org/10.1017/S0269889709990068

Stafford, B. M. (1984). Voyage into Substance: Art, Science, Nature, and the Illustrated Travel Account, 17601840. Cambridge (Ma): MIT Press.

Titos Martínez, M. (1997). Sierra Nevada: Una gran historia: Vol. I. Granada: Universidad de Granada.

Titos Martínez, M. (2014). Historia del esquí en Sierra Nevada: 1914-2014, 100 años de esfuerzo y pasión. Granada: Cetursa.

Willkomm, M. (1993). Las sierras de Granada (1882). Granada: Caja General de Ahorros y Monte de Piedad de Granada.

Withers, Ch, \& Livingstone, D. (2011). Thinking geographically about nineteenth-century science. En Ch. Withers \& D. Livingstone (Eds.), Geographies of Nineteenth-Century Science (pp. 1-20). Chicago: The University of Chicago Press. https://doi.org/10.7208/chicago/9780226487298.003.0001 